\title{
Rules of thumb and cultural evolution How simple heuristics have guided human adaptation and the emergence of cultural complexity
}

\author{
Roope O. Kaaronen ${ }^{1}$ \\ Mikael A. Manninen ${ }^{1}$ \\ Jussi T. Eronen ${ }^{1,2}$ \\ ${ }^{1}$ University of Helsinki: Helsinki Institute of Sustainability Science and Faculty of Biological and Environmental \\ Sciences, Past Present Sustainability Research Unit, Helsinki, Finland. ${ }^{2}$ BIOS Research Unit, Helsinki, Finland.
}

\begin{abstract}
This article combines insights from ecological rationality and cultural evolution to illustrate how simple heuristics - colloquially, "rules of thumb" - have guided human behaviour and the evolution of complex cultures. Through a variety of examples and case studies, we discuss how human cultures have used rules of thumb in domains as diverse as foraging, resource management, social learning, moral judgment, and cultural niche construction. We propose four main arguments. Firstly, we argue that human societies have a rich cultural history in applying rules of thumb to guide daily activities and social organization. Second, we emphasise how rules of thumb may be convenient units of cultural transmission and high-fidelity social learning - the backbones of cumulative cultural evolution. Third, we highlight how rules of thumb can facilitate efficient decision making by making use of environmental and bodily features. Fourth, we discuss how simple rules of thumb may serve as building blocks for the emergence of more complex cultural patterns. This paper sets a research agenda for studying how simple rules contribute to cultural evolution in the past, the present, and the Anthropocene future.
\end{abstract}

Keywords: cultural evolution; fast and frugal heuristics; social learning; embodied cognition; foraging; traditional ecological knowledge; cultural niche construction; simple rules; satisficing; phenological knowledge; offloading; judgment; decision making; ecological rationality 


\section{Introduction}

In studies on human decision-making, heuristics are often introduced in the context of how humans are not adaptive, or how heuristics bias our judgments and lead to suboptimal decisionmaking. This is especially evident in the research program of "heuristics and biases" (Kahneman, 2011; Tversky \& Kahneman, 1974; Thaler \& Sunstein, 2008). Recently, it has been argued that this overly negative focus on heuristics and biases in decision-making is a form of research bias itself (the "bias-bias" in behavioural science; Gigerenzer, 2018), and that more focus should be placed on the questions of why heuristic decision-making so often works and why heuristic or biased decision-making strategies have evolved to begin with (Gigerenzer, 2008a, 2018; Haselton et al., 2009; Hutchinson \& Gigerenzer, 2005; Johnson et al., 2013; Wilke \& Todd, 2010). This article aims to shed light on precisely these questions.

Research in ecological rationality has taken a different path than the heuristics and biases approach - one that asks questions better aligned with research in cultural evolution: Why is it that some heuristics or rules of thumb survive in common use, and often prove surprisingly adaptive in specific environments? Why is it that laypeople and cultures worldwide often rely on heuristics and

not logic, maximization of utility, or other optimization techniques, when making everyday decisions? Importantly, in the spirit of ecological rationality (and contrary to much of the heuristics and biases literature), the concepts "heuristics" and "rules of thumb" in this text are not used in a derogatory sense. Rather, the successful use of heuristics, as is shown below, can often be read as a testament to human ingenuity, traditional experience with local ecological systems, practical and efficient ecological knowledge, as well as human adaptivity.

Studying decision-making and heuristic problem-solving in the context of cultural evolution is important for various reasons. To grasp how and why complex human cultural practices and technologies have evolved, it is important to understand their cognitive precedents (Heyes, 2018, 2019). That is, what kinds of cognitive procedures and systems have enabled the evolution of complex cumulative cultures? Whilst recent research - such as Brand et al.'s (2021) study on the 
role of analogical thinking in cumulative cultural evolution, and Heyes' (2018) research on "cognitive gadgets" - has shed light on this question, much work remains to be done in providing empirically grounded and computationally plausible accounts of human cognitive evolution. Critics have argued that many prevalent cognitive models and computational models on human behaviour rely on unrealistically complex cognitive decision-making processes (Gigerenzer, 2008b; Waldman et al., 2020). For instance, many models assume some sort of optimization or utility maximisation as a starting point, yet when looking at human behaviour it is clear that in most cases such optimization is not possible or even an option (this applies even when humans "optimize under constraints"; see Gigerenzer, 2008b).

Therefore, as Gigerenzer (2008b, Ch. 1) suggests, cognitive research requires more psychological realism, and a move from "as if" theories to "realistic description" of how humans have made decisions and adapted to uncertain environments in the past and today - a move towards a "rationality for mortals". This will be helpful for developing more realistic quantitative and computational models of human evolution and adaptation in the past and for the future. For example, as Waldman et al. (2020, p. 1) note in a recent review, most contemporary climate adaptation models depict behaviour and decision making as "a rational utility-maximizing process", despite "decades of research demonstrating the prevalence of simpler heuristic choice when facing uncertainty and real-world constraints". ${ }^{1}$ Likewise, many economic models still rely on unrealistic assumptions of the homo economicus (see, e.g., Gigerenzer, 2008b and Henrich et al., 2001 for critiques). A more comprehensive anthropological understanding of heuristic decision-making is yet required.

In this paper we shed light on the role simple heuristics - or more colloquially, rules of thumb have played in the shaping of human cultural evolution and the emergence of complex forms of social life and ecological interactions. By studying domains of behaviour as diverse as foraging,

\footnotetext{
${ }^{1}$ One may speculate whether the relative neglect of heuristic decision-making has been a result of the bad reputation of heuristics owing to the "heuristics and biases" research programme, which almost exclusively framed heuristics as cognitive strategies that are inferior or at least unfavourable. See Gigerenzer (2018) for related discussion.
} 
subsistence, social learning, moral judgment, and cultural niche construction, and by providing a suite of descriptive case studies, we focus on four main arguments:

1. Human societies have a rich and variable history of applying rules of thumb in guiding their daily activities and social organization.

2. Rules of thumb are conveniently embedded in cultural norms, practical traditions, narratives, artefacts, and analogies, and may afford the spread of the kind of high-fidelity social learning and prosociality that are required for the evolution of complex cumulative cultures.

3. Rules of thumb make use of environmental and bodily features and can "offload" cognitive effort to the environment. This makes rules of thumb contextually sensitive, but in the right environments they can be cognitively efficient, conveniently transmissible, accessible, and reliable guides for human behaviour and social activities.

4. Rules of thumb are "cognitive gadgets" that can provide simple cultural building blocks, or scaffoldings, on top of which more complex cultural interactions, rules, and behaviours may emerge. $^{2}$

These arguments are informed by recent research in ecological rationality, cultural evolution, cognitive science, and complexity science. We consolidate the literatures of ecological rationality and cultural evolution, studying the role of rules of thumb in human adaptation and the emergence of complex human cultures. First, we briefly go through the theoretical backdrop of these arguments, then we discuss the four arguments outlined above by using exemplary case studies from the domains of subsistence, social learning, moral inference, and niche construction.

\footnotetext{
${ }^{2}$ Cognitive gadgets (Heyes, 2018, 2019) are "pieces of mental technology" that are assembled in the course of social and material interaction.
} 


\section{Key conceptual models and theoretical frames of reference}

\section{Ecological rationality}

Recent research in human behaviour and decision-making has emphasized how humans can manage complex tasks and navigate uncertain environments by making use of simple rules (Gigerenzer, 2008b; Marewski et al., 2010; Sull \& Eisenhardt, 2015; Todd \& Gigerenzer, 2012). Particularly, research on ecological rationality has uncovered how good judgments do not always require complex cognition, and can often be achieved by using simple heuristics (Marewski et al., 2010). Heuristics are simple strategies that are used when making decisions with limited time and information (Gigerenzer \& Todd, 1999b; Todd \& Gigerenzer, 2012).

It is often argued that people resort to heuristics because of limitations in cognitive capacity, metabolism, or energy efficiency. We, after all, have limited working memory, attentive capacity, energy, and cognitive capabilities at our use - therefore, rationality is necessarily constrained or "bounded" (Simon, 1972, 1990). But another rationale for the use of heuristics, one advocated by Herbert A. Simon (ibid.) and recently by research in ecological rationality, is the notion that with many (if not most) everyday problems, optimal solutions are unknowable since problems are nebulous, poorly defined or computationally intractable/hard (Callebaut, 2007; Kozyreva \& Hertwig, 2019; Simon, 1972, 2000). In the complex environments we inhabit, the consequences

of our actions always remain, at least to some degree, uncertain. Under radical or fundamental uncertainty (Kay \& King, 2020; Arthur, 2021) - situations where costs, benefits, or causal effects are unknown - one cannot rely on text-book protocols for decision-making, yet decisions have to be made nonetheless (Simon, 1972).

It follows that heuristics are not used merely because of cognitive efficiency, but they are ultimately necessary for navigating a complex, variable, and uncertain world. The ecological aspect of ecological rationality follows naturally from this: in an uncertain world, rationality cannot be defined as an optimisation process, but rather as the fitness between cognitive strategies and environmental structure. Hence, "rationality is not logical, but ecological" (Gigerenzer, 2004). Or, 
as per Simon's (1990) analogy of a pair of scissors, the mind and the environment form the two blades that serve as the cutting edge of rationality. Even simple heuristics can exploit the structures of the environment, making use of statistical regularities and ecologically valid cues to make reliable inferences.

"Ecological validity" here means the degree of correlation between a proximal cue and a distal variable (the target of inference) to which it is related (Hammond, 1998). As is discussed below, many cultural traditions make use of simple proximal cues to infer the presence of correlated distal variables. In this sense, decision-making can be partly offloaded to the environment (Risko \& Gilbert, 2016; see also Constant et al., 2019; Clark \& Chalmers, 1998): the cognitive demand for information processing may be considerably reduced if reliable environmental features are utilised in decision-making. Offloading of this kind is a recurrent theme in the case studies below.

Heuristics can be "fast and frugal", using one-reason decision-making or other simple inferences (e.g., ecologically valid cues) to make decisions (Gigerenzer \& Todd, 1999a). Heuristics can also guide behaviours that satisfice, settling on outcomes better than current ones or ones that meet a pre-defined aspiration level. ${ }^{3}$ See also (Marewski et al., 2010; Todd \& Gigerenzer, 2012) for useful overviews of how and where fast and frugal heuristics or satisficing strategies have been shown to work.

If the fitness of cognitive strategies is a function of the mind and the environment, it is reasonable to assume that many cognitive strategies have adapted specifically to their local ecological niche, making efficient use of local environmental cues. Whilst heuristics often also depend on genetically evolved abilities of our cognitive and bodily systems (e.g., pattern recognition, associative/social learning, and physical dimensions of the human body), the focus of this paper is mostly on culturally evolved heuristics. Like any evolutionary adaptations, heuristics are not inherently

\footnotetext{
3 Satisficing is a neologism introduced originally by Herbert A. Simon (1956), a portmanteau from "satisfy" and "suffice" - satisficing aims at adequate or satisfactory outcomes (and not for an optimal solution), and involves searching through available alternatives until a threshold for acceptability is met.
} 
"good" or "bad". Rather, heuristics are most successful in the environments in which they have evolved or to which they are adapted (Todd \& Gigerenzer, 2007).

In practice, simple heuristics have been shown to be capable of outperforming more complex cognitive strategies. For instance, famously, in a game-theoretical competition for the iterated prisoners dilemma, the simple heuristic algorithm Tit-for-Tat ${ }^{4}$ proved to be the most successful - it was also the simplest algorithm in the competition (Axelrod \& Hamilton, 1981). Elsewhere, research in ecological rationality has worked to improve decision-making in medical contexts (Gigerenzer \& Kurzenhaeuser, 2005), and illustrated situations where one-reason decisionmaking can outperform more complex statistical models (Czerlinski et al., 1999). In practice, it turns out, simple rules can often outperform more complex ones (Goldstein \& Gigerenzer, 2008).

However, research in ecological rationality and fast and frugal heuristics has traditionally focused on well-defined and algorithmic decision-making processes (such as decision trees, e.g., Berretty et al., 1999; Martignon et al., 2008), and still has a dearth of examples and case studies from realistic everyday behaviours. Moreover, plausible accounts of how heuristics may have shaped our evolutionary past are lacking. This is something that we here seek to correct, mainly by studying how cultures worldwide have developed rules of thumb to guide even complex everyday behaviours. Whilst many of the heuristics discussed here may be described as fast and frugal, others do not quite meet these criteria. For this reason, in the following these simple rules are referred to with the more general concept, "rules of thumb".

Whilst rules of thumb can be fast and frugal heuristics, they can also be what Sull \& Eisenhardt (2001; 2015) call "simple rules": how-to rules (rules that guide successful behaviour), boundary rules (rules that define the boundaries for safe or successful behaviour), or other heuristics that resemble rough guidelines or principles. As is illustrated below with many case studies, such rules of thumb can be embedded in norms, traditions, and technologies, and can make use of analogies

\footnotetext{
${ }^{4}$ The Tit-for-tat strategy starts by naively cooperating and then proceeds to do whatever the other player did on the previous move.
} 
or simple relationships between environmental, bodily, or cognitive components. Typically, a rule of thumb is defined as something based on practical knowledge rather than theoretical understanding (OED Online, 2021). This also applies in the present text. The following working definition of "rule of thumb" is used in the remainder of this text:

Rule of thumb. A rule of thumb is a cognitive shortcut used for making inferences or guiding behaviours. It is typically based on practical rather than theoretical/scientific knowledge. Rules of thumb may be contextually sensitive "fast and frugal" heuristics, one-reason decisions, simple if/then rules, or rules based on, e.g., simple proportions/ratios and environmental regularities (ecological validities). Rules of thumb seek to satisfice rather than optimise. Rules of thumb may be used successfully without causal or scientific understanding of why they work.

\section{Cultural evolution and high-fidelity social learning}

Recently, research in cultural evolution has emphasized the role of social learning in human adaptation, with social learning being highlighted as one of the major factors that explain human ecological success (Henrich, 2015). A particularly important aspect of social learning is highfidelity cultural transmission, the accurate transmission of a cultural trait or behaviour from one individual to another (Henrich, 2015; Laland, 2018; Muthukrishna \& Henrich, 2016). The survival and reproduction of cultures has been fundamentally dependent on cumulative bodies of accurately transmitted information, and particularly information related to hunting, foraging (and food production/procurement more generally), medical knowledge, technical manufacture, as well as other everyday necessities (Atran \& Henrich, 2010; Henrich, 2015). However, whilst many theories of social learning emphasise how important high-fidelity social learning is for the development of cumulative culture, less focus has been alerted to questions such as what kinds of 
units of knowledge are suitable for cognitively efficient and high-fidelity learning (although see, e.g., Brand et al., 2021; Norenzayan et al., 2006).

Rules of thumb often make use of simple environmental cues and reliable geometric or bodily ratios - indeed, even the etymology of "rule of thumb" derives from the use of rough measures such as "thumb-width" by artisans and manual workers. ${ }^{5}$ A rule of thumb is therefore often a convenient and easily memorable unit of cultural transmission, since it makes use of recurrent environmental (or bodily) structures and regularities, effectively offloading much cognitive effort to the ecological niche. Consequently, rules of thumb are "bite-size" cognitive shortcuts that are easy to learn (and teach) through practical activities and embed into tradition, artisanship, material artefacts, or social structures such as master-apprentice relationships. They break complex decision-making into structures that are easily enacted, learned, copied, and taught. As is shown below, rules of thumb are also often embedded in mnemonics, stories or analogies, which have been previously identified as forms of conveniently transmissible epistemic units (Brand et al., 2021; Norenzayan et al., 2006). The fact that bodily ratios are used so often as rules of thumb also aligns well with recent research in embodied cognition (e.g., Barrett, 2011; Malafouris, 2013), which has emphasised how cognition is "deeply dependent upon features of the physical body of an agent" (Wilson \& Foglia, 2011).

Importantly, the use of rules of thumb does not require the understanding of causality - one can well make use of culturally inherited rules of thumb without understanding why they work. This is a recurrent pattern in the case studies below. This argument, related to the "collective brain" theory in cultural evolution (Henrich, 2015; Muthukrishna \& Henrich, 2016), implies that rules of thumb can be entirely atheoretical, and even products of haphazard innovation or "cultural drift" (gradual, uncontrolled variation). When rules of thumb are experimented with through trial and

\footnotetext{
${ }^{5}$ A very persistent myth claims that the phrase "rule of thumb" has its origins in domestic violence. Purportedly, a "law allowed a man to beat his wife with a stick so long as it is was no thicker than his thumb". Since it would be distasteful to use a concept with such a grim etymology, we highlight that this folk etymology is entirely fictious and no such law ever existed (Martin, 2021).
} 
error, or when they emerge haphazardly, they may be transmitted differentially based on their adaptive value, particularly through cultural norms and practical traditions.

Another recurrent theme in this paper is that rules of thumb afford not only high-fidelity social learning, but they can also promote individual learning through trial-and-error exploration. This is because rules of thumb often serve as boundary rules, setting explicit guidelines and scaffoldings that guide individual behaviours. In this respect, rules of thumb can be forms of explicit knowledge which afford the learning of experiential tacit knowledge (Polanyi, 1969, 1974, 2009), thus facilitating the accumulation of complex individual skills, such as foraging expertise.

\section{Simple rules and the emergence of complexity}

A further rationale for studying the role of simple rules in cultural evolution has its roots in complexity theory. Throughout the past few decades, research in complex systems has time and again illustrated how complex macro-scale patterns can emerge from simple micro-scale principles and interactions (Kauffman, 2008, 2019; Mitchell, 2009; Wilensky \& Rand, 2015).

For example, the interaction of simple rules in agent-based models or cellular automata (e.g., Conway's Game of Life, Fig. 1) can give rise to surprisingly complex emergent wholes with altogether unpredictable macro-level properties. Moreover, complex and collective-level phenomena (such as flocking birds, schooling fish, or urban segregation patterns) can be modelled by agents relying on relatively simple rules, even simple heuristics (Wilensky \& Rand, 2015; Schelling, 2006). This phenomenon is broadly known as "emergence": even uncomplicated microlevel rules and interactions can bring about complex and unpredictable macro-scale outcomes (Kauffman, 2008, 2019; Mitchell, 2009).

This invites us to consider the effects simple rules such as heuristics or rules of thumb may have in the emergence of complex cumulative cultures. In fact, complex systems research has inspired a rule of thumb itself, known as Gall's law. "A complex system that works is invariably found to have 
evolved from a simple system that worked" (Gall, 1975). Well-functioning complex systems of social rules, interactions, or norms may have evolved from simpler practical rulesets, such as rules of thumb or heuristics. Below, we discuss some cases where simple rules have preceded the evolution of more complex rules, behaviours, or norms. One major recurrent caveat is that the use of rules of thumb itself may presuppose more complex embodied skills and traditional knowledge frameworks. As such, heuristics often are complementary to (and not substitutes for) other modes of knowing.

Figure 1. A virtual Petri dish: screenshot of John Horton Conway's (1970) Game of Life on NetLogo (Wilensky, 1998, 1999). A random configuration of dark pixels ("agents") on the left gives rise to stable, symmetric, moving, reproductive, and often "lively" complex patterns (right) once the agents are subjected to only four rules. The Game of Life remains one of the most famous agent-based models where complexity emerges from simple rules.
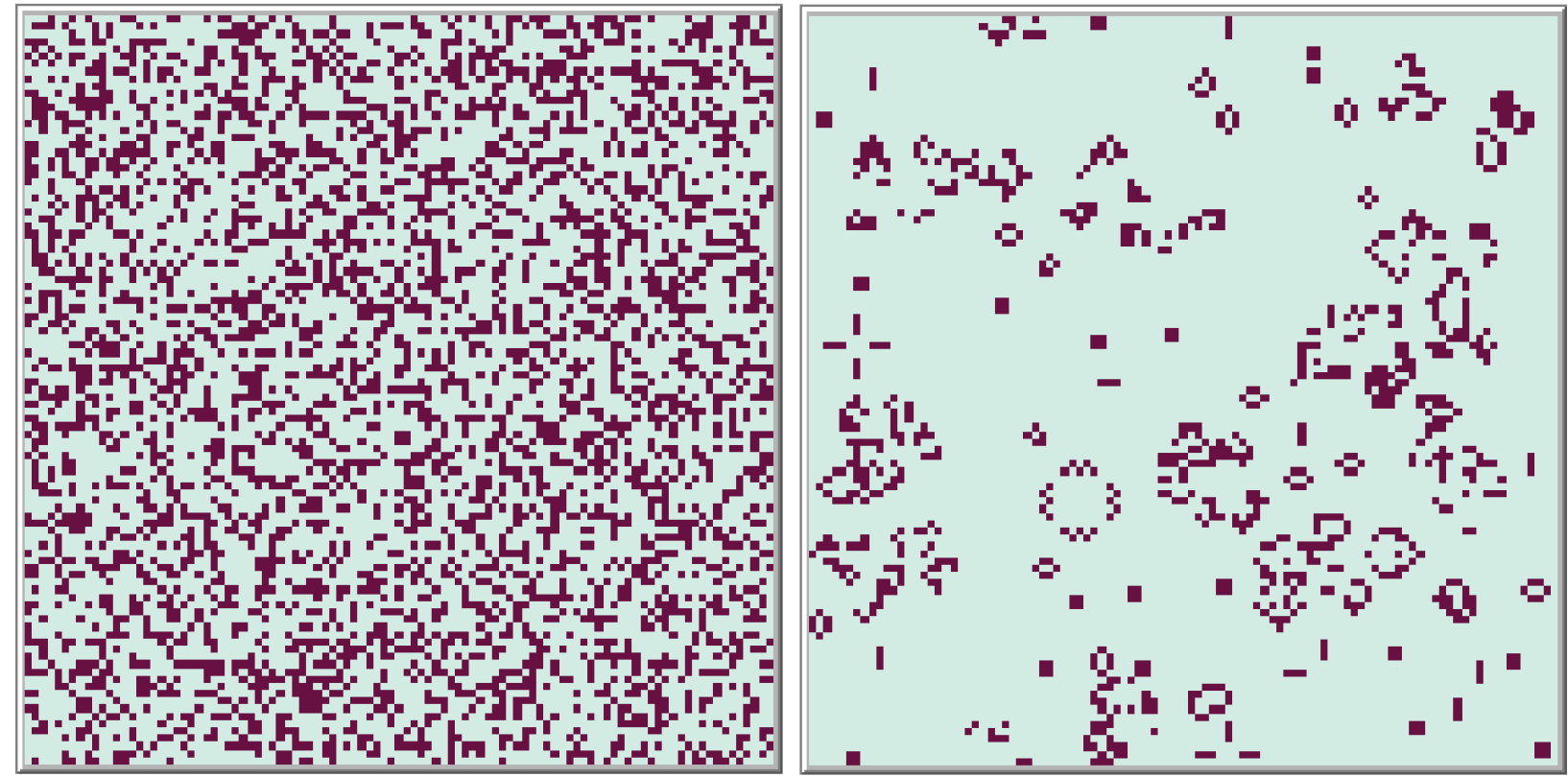


\section{Varieties of rules of thumb: case studies and discussion}

\section{Natural cues: rules of thumb in subsistence}

Making good and efficient decisions in food procurement and production is paramount for the evolution of complex human cultures. Avoiding poisonous foodstuffs, or timing activities such as sowing, hunting, fishing, and harvest, are central to cultural continuity and reproduction. Therefore, studying decision-making in these contexts warrants special attention.

\section{Phenological knowledge}

One recurring theme in literature on local, small-scale, practical, traditional, and indigenous ecological knowledge is the use of bioindicators and phenological knowledge in decision-making. Phenology refers to the study of periodic/seasonal events in biological life cycles. Phenological knowledge makes use of recurrent ecological events, such as the flowering of particular plants or the arrival of migratory birds, to, for instance, open and close resource exploitation seasons (Prober et al., 2011; Smyth \& Isherwood, 2016; Colding \& Folke, 2001).

Often, phenological knowledge makes inferences based on a single cue, such as the appearance of a specific bioindicator (e.g., a plant or an animal). As Lantz and Turner (2003) note, since phenological events usually occur in a reliable sequence, one event may be used to indicate other resource related activities. This often affords simple "if/then" rules, which use one event ("if $x$ occurs") to guide another ("then do $y$ "). Traditional ecological knowledge has for long recognized the value of phenological indicators as ecologically valid cues for guiding complex cultural patterns. These rules of thumb can efficiently offload vital decisions to the environment by making use of biological regularities. Since these rules rely upon local ecosystem features rather than universal systems (such as the Gregorian calendar), they are particularly well-adapted to deal with local variance in, e.g., weather conditions. 
Among Aboriginal Australians and Torres Strait Islander peoples, the use of phenological rules of thumb is common. ${ }^{6}$ According to Smyth \& Isherwood (2016), this can involve:

- "The opening and closure of seasonal exploitation of particular resources marked by ecological events, such as the flowering of particular plants or the arrival of migratory birds", or

- "Restriction on the harvesting of particular species based on age, gender, reproductive conditions, health, fat content etc. of individual animals."

Prober et al. (2011) also note, in their Australia-wide review of Australian Aboriginal Peoples' seasonal knowledge, how some Australian Aboriginal communities use cues such as "weather, plant flowering events, and other seasonal indicators" to point to the arrival, breeding status, or condition of terrestrial or marine fauna.

Similarly, the traditional Javenese seasonal calendar PranotoMongso makes use of bio-indicators to guide resource management (Retnowati et al., 2014). Rural communities in Gunungkidul, particularly farmers, are familiar with PranotoMongso, applying it mainly in agricultural practices. PranotoMongso knowledge is used, for example, to identify the start of the rainy season from the bud of Gadung yam (Dioscorea hispida), which indicates increasing air humidity. The start of the dry season, in turn, can be identified from the outbreak of cotton tree (Ceiba pentandra) or the sound of the coconut bug (Oryctes rhinoceros). The timing of rainy and dry seasons is valuable knowledge for the timing of cultivation or harvest.

In Retnowati et al.'s (2014) qualitative research on Javanese use of the PranotoMongso, all interviewees knew some bioindicators for seasonal changes. These skills are not taught formally in

\footnotetext{
${ }^{6}$ In the following examples, we aim to write, as specifically as possible, about the phenological knowledge used by specific cultural or ethnic groups. This is important, since local knowledge is always contextually sensitive, and generalizing on larger or more abstract levels can be problematic. However, sometimes, such as in this case, the source material is not specific enough to pinpoint a specific cultural or ethnic group.
} 
school, but rather passed on from the elderly to young farmers through stories, traditional narratives, observation, and direct experience (Retnowati et al., 2014).

Similar rules are used by the indigenous peoples of British Columbia and surrounding areas. Lantz $\&$ Turner's (2003) survey of ethnographic literature documented over 140 examples of traditional phenological indicators. These traditional rules indicate timings of plant and animal resource availability or abundance. They are also used to predict changes in weather and seasons. Notably, Lantz \& Turner (2003) found that approximately half of the documented rules are direct indicators that use the appearance of one species to signal the onset of another. Therefore, many phenological indicators resemble fast and frugal heuristics, using a single ecologically valid cue to draw an inference regarding the (imminent) availability of another species or resource. Some examples follow (see Lantz \& Turner (2003) for many more):

- The Nlaka'pamux people use the blooming of wild rose (Rosa spp.) to indicate that soapberries (Shepherdia canadensis) are ready for harvest.

- The Nlaka'pamux also use the leafing of desert currant (Ribes cereum) to signal that the steelhead trout (Oncorhynchus mykiss) are running in a local river. The proper timing of fishing is particularly important since a mistimed harvest might endanger the long-term availability of the resource.

- Rules of thumb may also embed causal claims: it is believed in various indigenous traditions in British Columbia that the singing of the Swainson's thrush (Hylocichla ustulata) brings about the ripening of salmonberries (Rubus spectabilis).

Similar phenological knowledge has been reported in, for example, communities in the Delta State of Nigeria (Fitchett \& Ebhuoma, 2018) and various Native American communities (Chisholm Hatfield et al., 2018). In one study at the Seine River First Nation (Haines, 2017), the efficacy of traditional phenological heuristics (first sightings of Eastern tiger swallowtail, Papilio glaucus) was compared to more modern scientific measurements (e.g., water temperature) to predict the 
spawning of lake sturgeon (Acipenser fulvescens). Whilst the latter was more accurate, the swallowtail-heuristic was still shown to be remarkably precise.

In like manner, examples from Sápmi ${ }^{7}$ and Finland show how traditional knowledge utilises phenological heuristics in resource procurement. Skolt Saami tradition from Suõ'nn'jel instructs to gather inner bark from pine trees (Pinus sylvestris) when Labrador tea (Rhododendron tomentosum) blooms (pine cambium is used for baking bark bread). In Finnish tradition, the sowing of flax is traditionally timed with the flowering of the bird cherry (Prunus Padus) - the same rule has been dated as far as the 1600s in Sweden, and has also been used in Estonia and Lithuania (Kaukonen, 1946). In Finnish tradition, it has been noted that birchbark, which is used particularly for tinder but also for crafts, is best removed from a growing tree while rye blooms (Laine, 1944). Various traditional rules of thumb may also guide pastoral activities. For example, some western North Saami reindeer herders make use of the following rule of thumb: "if pastures run out or if a reindeer is separated from their herd, search for reindeer in the magnetic north". Whilst this heuristic is born from practical experience and tradition, it may have its roots in deer species' natural instincts to align with the Earth's magnetic field (see Begall et al. 2008). ${ }^{8}$

Rules of thumb are commonly used to complement more complex cultural traditions and processes. Simple heuristics which use ecologically valid cues to guide, e.g., cultivation or harvesting, may also be embedded in complex cultural systems, as famously illustrated by Lansing (1987). Lansing's work on Balinese water temples emphasized that whilst Balinese rice cultivation is timed accordingly with the full-moon of a specific month, this simple environmental cue is only used to commence a much more complex series of cultural events that involve various rituals, ceremonies, and complex forms of social cooperation that ensure successful harvest and pest control.

\footnotetext{
${ }^{7}$ Sápmi is the cultural region in northern Fennoscandia traditionally inhabited by the Saami (also Sámi, Sami) people.

${ }^{8}$ The Saami examples in this paragraph are based on personal communication with colleagues with expertise in traditional Saami practices. The reindeer herding example is from Oula A. Valkeapää, an experienced reindeer herder from Gová-Labba siida.
} 
Altogether, the use of simple heuristics does not - and this should be stressed - imply that the cultural frameworks these heuristics are embedded in are simple. Rather, the use of rules of thumb is a testament of the capacity of local forms of traditional ecological knowledge to make efficient and adaptive use of ecologically valid cues.

\section{Foraging}

Diverse uses of bioindicators and ecological cues may also guide foraging behaviours. Research on mushroom foraging societies in Finland illustrates how simple rules of thumb are utilised to guide safe and efficient foraging (Kaaronen, 2020a). Mushroom foraging is potentially perilous: edible mushrooms are often hard to distinguish from poisonous lookalike species, and deadly mushrooms are abundant. Regardless, mushroom foraging is very common in Finland, fatal accidents are rare, and mushroom hunting is considered a form of intangible cultural heritage (Kaaronen, 2020a; Elävä perintö, 2019). The cultural practice is partly preserved by Finnish “everyman's rights", which allow free roaming in nature regardless of who owns or occupies the land (Ministry of the Environment, 2019).

Much of the foragers' success in this uncertain environment can be attributed to relatively simple rules. Mushroom foraging heuristics include simple recognition-type heuristics (see also Goldstein \& Gigerenzer, 2002), such as "don't pick mushrooms you don't recognize", as well as other decision-making rules that altogether preclude the picking or eating of specific subsets of potentially dangerous mushrooms (Kaaronen, 2020a). The latter case is best exemplified by the commonly reported fast and frugal heuristic: "avoid all white mushrooms". The rationale for this rule of thumb is the high prevalence of a deadly white mushroom species, Amanita virosa (Fig. 2).

Foraging heuristics are used particularly to establish safe boundary rules for foraging practices (Kaaronen, 2019, 2020a). These have also been called “applied precautionary heuristics” (Kaaronen 
et al., 2021). ${ }^{9}$ In the practice of mushroom foraging, it is first and foremost important to avoid risk of ruin - in this case consuming a poisonous mushroom. A forager does not typically seek to optimise their catch, but rather seeks to avoid worst outcomes (Kaaronen, 2020a; 2020b, Chapter 3.3). This is a particular case where cognitive biases may protect foragers from deadly environmental variance (see also Johnson et al., 2013) - since making correct rejections is paramount ${ }^{10}$, it may be more adaptive to bias one's search for subsets of mushrooms that don't include any poisonous species (even if this means missing some edible ones).

The basic boundary rules also serve as instructional scaffoldings (Van Der Stuyf, 2002) that allow even a child to participate in the practice of foraging, and develop expertise through individual exploration. In this case, knowing the basic boundary rules enables the development of a more sophisticated perceptual awareness, enabling further interaction with new affordances in the foraging environment and subsequent individual learning (Kaaronen, 2019, 2020a, 2020b; Ingold, 1996).

Foragers also use other fast and frugal heuristics to make inferences about edibility, such as using the simple cue of white milk to identify edible species of mushrooms in the genus Lactarius. A commonly reported heuristic is that any Lactarius that bleeds white latex when cut is edible although this is not a foolproof strategy, it satisfices and doesn't lead to fatal mistakes (Kaaronen, 2020a). Many other similar heuristics that make use of ecologically valid cues are reported in (Kaaronen, 2020a).

\footnotetext{
${ }^{9}$ Elsewhere, similar precautionary heuristics have been documented to be embedded in culturally transmitted taboos. For example, Fijian taboos prohibit the eating of a specific (toxic) fish species during pregnancy and breastfeeding, effectively reducing cases of fish poisoning in pregnant and lactating women (Henrich \& Henrich, 2010).

${ }^{10}$ This is because the payoffs are asymmetrical: a false positive error (eating a poisonous mushroom) is much more costly than a false negative error (dismissing an edible mushroom). Error Management Theory predicts that under such conditions, a cognitive bias that prevents false positives would increase fitness and be "adaptively rational" (Johnson et al., 2013). Kaaronen's study (Kaaronen, 2020a) validates a simulation study by Bullock and Todd (1999, p. 533), who argue that precautionary foraging strategies are essential in an environment with lethal mushrooms.
} 
Figure 2. Specimen of Amanita virosa, commonly known as the "destroying angel", in southern Finland. Particularly young $A$. virosa (bottom row) may be mistaken for one of several edible mushroom species such as those in the genus Agaricus (which are relatives of the portobellos/champignons commonly found in supermarkets). Such a mistake could well be deadly, since $A$. virosa is one of the most poisonous mushrooms in the world - eating just one cap can kill an adult human. For this reason, many Finnish mushroom foragers report altogether avoiding white mushrooms, even though edible white species are plentiful. Pictures by Roope O. Kaaronen.
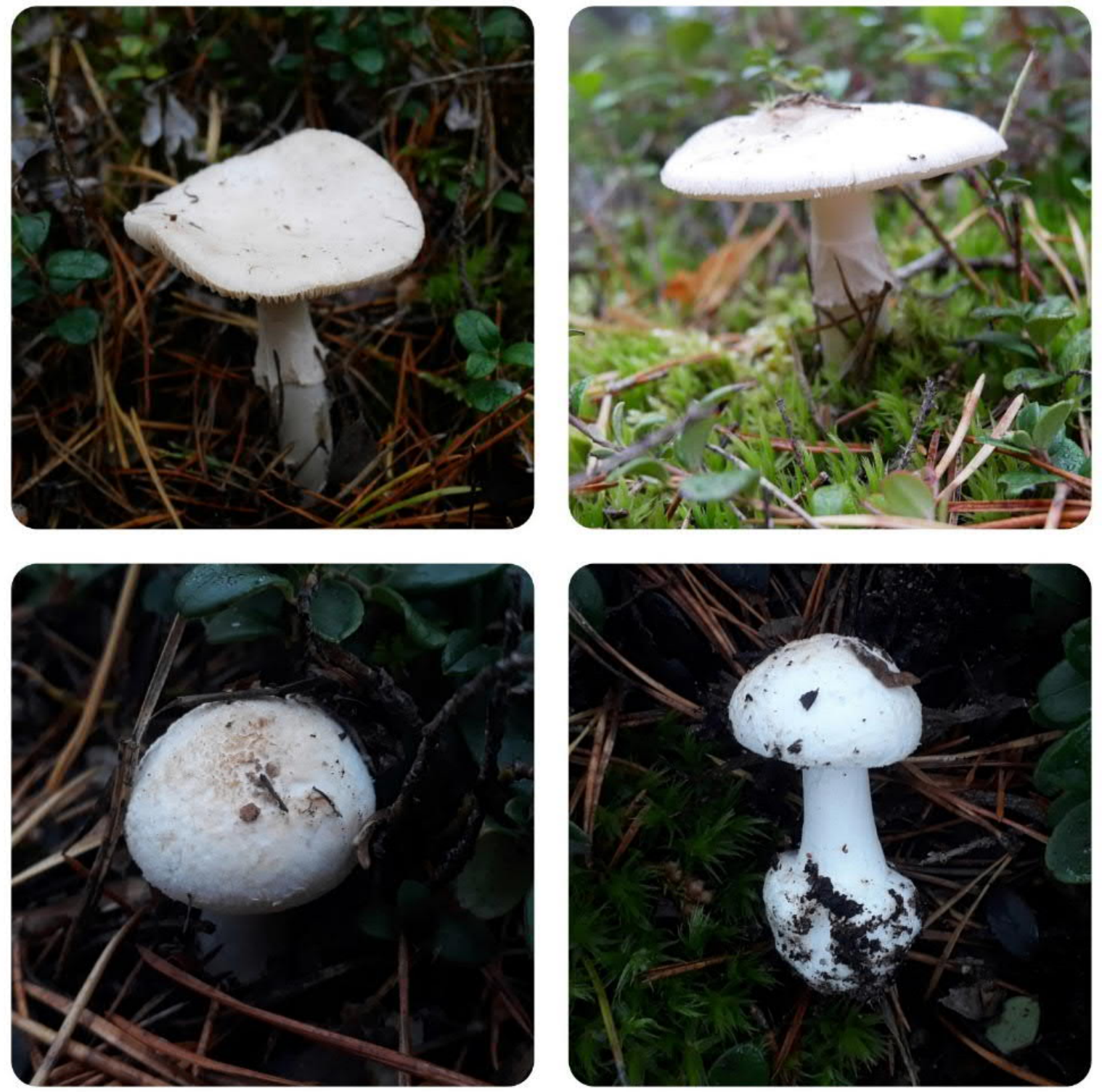
Foraging heuristics can also be embedded in mnemonics or analogies (see also Brand et al., 2021 for discussion on analogies as a key component of cultural evolution). Most Finnish mushroom foragers report learning the practice of mushroom foraging from their parents, and owing to this vertical cultural transmission it is unsurprising that some foragers report quite idiosyncratic mnemonics or analogies for mushroom identification:

"Cortinarius caperatus is a Northern chap sitting by a bonfire: frost on his cap, an aurorashaped scarf above his collar, and when young, a total prick [a reference to its phallic shape when young]."

In the same study, some foragers also reported using rules of thumb even whilst not completely sure why they were used at all. For instance, one forager reported bluntly: "I do not pick white mushrooms. I don't know why." This highlights again that culturally transmitted rules of thumb may sometimes outsmart the individuals using them. Rules of thumb may form a part of the socalled collective brain that guides decision-making even when individuals are unaware about the reasons for doing so (Henrich, 2015; Muthukrishna \& Henrich, 2016).

It should also be stressed that the simple rules of thumb used by Finnish mushroom foragers are far from the only forms of knowledge used in decision-making. Many foragers are well-versed even in scientific mycology, and the practice is thoroughly infused with tacit knowledge and practical expertise. In fact, many heuristics presuppose more elaborate skills: for example, the "white milk" heuristic discussed above presupposes the capacity to identify a mushroom in the genus Lactarius, which is not altogether a simple feat. However, rules of thumb can be used complementarily to more complex knowledge systems (as also emphasized in Kaaronen, 2020a).

Rules of thumb may also guide the search activity itself: indigenous Nahua mushroom gatherers have been reported to use a heuristic searching procedure: "search with slower and more tortuous movement after a recent encounter with a food item (intrapatch search) and move with more rapid and linear movement otherwise ("interpatch" search)" (Pacheco-Cobos et al., 2019). Similar heuristics that guide physical movement and search/exploration were also reported in Kaaronen's 
(2020a) foraging study. Overall, decision-making in foraging/hunting practices has received relatively little attention, and further research could uncover whether other foraging cultures use or have used similar heuristic strategies as described above.

\section{Not so simple: when rules of thumb fail and challenges of the Anthropocene}

The structure of ecologically rational decision-making dictates that traditional heuristics may no longer function when ecological systems change or degrade. This aspect of decision-making is also why ongoing climate and environmental changes affect us on a deeper level than being "just" new conditions - once old regularities are no more, new adaptations are necessary (Kaaronen et al., 2021). The new cognitive challenge of developing alternative cognitive coping and adaptation strategies will be most pronounced where ecological systems are most radically changed (e.g., snow- or ice-covered landscapes) or where biodiversity loss is most severe. This is one reason why the Anthropocene and related climatic and ecological changes (Barnosky et al., 2012; A. Barnosky \& Hadly, 2015; Steffen et al., 2015) present such a notable breaking point for human cultural evolution (Kaaronen et al., 2021). For example, in Gunungkidul, farmers are now "questioning the effectiveness of PranotoMongso" due to climate change and loss of biodiversity and indicator species (Retnowati et al., 2014).

Moreover, traditional rules of thumb and practical knowledge are also endangered by cultural homogenisation. For a historical example, Retnowati et al. (2014) note that Javanese traditional ecological knowledge suffered greatly during Dutch colonialism (the Dutch Cultivation System or cultuurstelse), enforced especially in Java, resulting in famines and epidemics in the 1840s. Lansing (2006) in turn documents how the Green Revolution in Indonesia in the 1970s - which endangered many traditional forms of environmental management - had dire consequences for both environmental sustainability and food production. In such cases, traditional and practical rules (some of which utilise rules of thumb) have indeed outperformed higher-technological approaches (see also Scott, 1998 for similar discussion). 
Rules of thumb may also cease to work when populations migrate from one environment to another. Mushroom foraging accidents have been reported to be particularly prevalent in relocated populations, having occurred, for example, when refugees use their native foraging rules in their new home country (Kaaronen, 2020a; Connolly, 2015). In the Anthropocene and its characteristic mass migrations (Xu et al., 2020), this will prove to be an extra challenge for traditional knowledge.

\section{Cultural biases: rules of thumb for social learning}

Most rules of thumb discussed in this text are socially learned, insofar as these rules are "facilitated by observation of, or interaction with, another individual or its products" (as per the definition of "social learning" by Hoppitt \& Laland, 2013). However, the specific ways in which humans use heuristics or rules of thumb in deciding (intentionally or unintentionally) whom to learn from also warrants inspection.

Recent theoretical advances in cultural evolution suggest that selective and preferential social learning, or learning strategies that bias certain models over others (a "model" in social learning jargon is someone learned from or copied), is central in the accumulation of cumulative culture (Jiménez \& Mesoudi, 2019). Copying others is often adaptive, since it effectively offloads cognitive processing and costly individual trial-and-error learning to one's conspecifics (Mesoudi, 2011, p. 17). It has for long been suggested that humans copy others on the basis of success or skill - e.g., a mushroom forager may choose to follow the path of another forager carrying a hefty basket of catch - but the fact remains that success as such is often difficult to judge, particularly when environments are variable and luck is involved (Jiménez \& Mesoudi, 2019). Therefore, more crude cues may have to be used when ranking the order of which models to copy, and it turns out this is often accomplished by using simple heuristics.

Henrich \& Gil-White (2001) have proposed that humans use adaptive inferential short-cuts to guide the decision of which model(s) to learn from or copy in a social group. One suggested heuristic for social learning is known as prestige bias. In prestige-biased social learning, humans 
"copy the behaviours of individuals highly respected and admired in a social group (i.e., prestigious individuals)", and disproportionately prefer copying prestigious individuals over less prestigious ones (Jiménez \& Mesoudi, 2019). Whereas success or fitness may be difficult to judge as such, prestige may be easier to assess based on simple cues. These simple cues can roughly be divided into two kinds (based on Jiménez \& Mesoudi, 2019).

With first-order cues, learners can use cognitively efficient short-cuts by making inferences from simple traits (e.g., appearance, personality, material possessions, etc.) of models (Jiménez \& Mesoudi, 2019). For example, since age is often correlated with accumulated cultural knowledge, learners may use age as a cue to rank models. The age-heuristic, like any ecologically rational decision, only works in specific contexts. For instance, biased copying of elderly people may only work in environments where the structure of the environment changes at a slow rate, since otherwise old skills may have expired. The age-heuristic is perhaps most often used by children copying adults (Heyes, 2018). Other first-order cues identified in Jiménez \& Mesoudi’s (2019) meta-analysis include generosity (since success is a prerequisite for surplus), self-confidence, and cultural titles. Cues such as sex, ethnicity, dialect or self-similarity may also guide preferentially biased learning (Henrich \& Henrich, 2007; Acerbi, 2019).

Second-order cues are cues where social learners select models based on the behaviour of other individuals (Jiménez \& Mesoudi, 2019). Heuristics can direct frequency-dependent behaviour (Kendal et al., 2009) where people, for example, copy those models who are most copied by others, adopt a behaviour once a certain proportion of acquaintances convey that behaviour, or disproportionately copy the most common behaviour in a social group (the latter is known as “conformism”, see Henrich \& Boyd, 1998; see also Centola $(2018,2021)$ for frequency-dependent adoption of novel behaviours).

As any other heuristic, rules of thumb used in social learning are malleable cognitive gadgets tied to time and place. Many cues may be inherently subjective to the culture or subculture studied. For example, an elderly person could well use the rule of thumb "copy a teenager" when trying to 
navigate the complex online environments of the digital world, effectively inverting the ageheuristic as described above. Again, to drive the point home: these simple heuristics are fallible, but when used in the right context (and with a right amount of scepticism and contextual awareness; see, e.g., Acerbi, 2019, Chapters 3 and 4) they can provide a sufficiently reliable framework on the basis of which more complex social interactions may emerge.

\section{Religion, law, and reciprocity: moral rules of thumb}

Rules of thumb are also abundant in moral judgments, ethical codes, religious texts, and codes of law. Those embedded in Christian or Jewish traditions, for instance, will likely readily cite some of the simple rules in the Ten Commandments (e.g., "Thou shalt not steal"). Similar heuristic ethical codes are also found, for instance, in the Five Precepts of Buddhism and the ethical codes of Confucianism. Broadly speaking, many of these ethical codes could be thought of as conveniently transmissible rules of thumb that designate rough boundaries for social interactions. Importantly, these rules of thumb generally serve the purpose of promoting prosociality, which is an essential prerequisite for the development of large-scale complex cultures (Atran \& Henrich, 2010; Norenzayan et al., 2016).

One of the more notable heuristics in world religions is the "Golden Rule", which is commonly transcribed in English as "Do unto others as you would have them do unto you". The Golden Rule is, effectively, a simple rule of thumb used to guide reciprocal and prosocial behaviour. Various versions of The Golden Rule have been traced to several locations in the Ancient world (e.g., Egypt, India, Middle-East, Greece and Rome), and versions of it can be found in most major world religions, including Judaism, Zoroastrianism, Islam, Christianity, Buddhism and Confucianism (Gensler, 2013; Neusner \& Chilton, 2008). To point out some examples (see Neusner \& Chilton, 2008 for many more): 
- Davis (2008, p. 146) notes how the ancient Jain collection, the Sutrakritanga (1.11.33), includes the following passage: "A man should wander about treating all creatures as he himself would be treated.”

- Moazami (2008, p. 68) cites the most quoted Zoroastrian Golden Rule in Book VI of the Dēnkard: "that character is best, one who does not do to another that which is not good for himself."

Of course, the extent upon which the Golden Rule in its various forms has in practice shaped moral behaviour is variable, contextual, and debatable (for such discussion see Neusner \& Chilton, 2008). For instance, depending on religions and scriptures, the Golden Rule may promote reciprocity on a continuum from intracultural (within-group) to intercultural (between-group) interactions (Green, 2008b), and may be applied variably between social hierarchies (this is particularly the case with Hindu and Confucian applications of the Golden Rule; see Csikszentmihalyi, 2008; Davis, 2009). Regardless, its prominence itself is likely a testament to its prosocial utility in the self-organization of complex cultures. Wattles (1996, p. 188; in Green, 2008a) emphasizes how the Golden Rule is the kind of intuitive rule of thumb that is conveniently transmissible:

"The golden rule is, from the first, intuitively accessible, easy to understand [...] The rule tends to function as a simplified summary of the advocate's moral tradition, and it most commonly expresses a commitment to treating others with consideration and fairness, predicated on the recognition that others are like oneself."

Although this is somewhat speculative, easily graspable rules of thumb such as these may have served to sustain or increase group solidarity or reduce intra-group competition and freeriding all important precursors to the "rise of stable, large, cooperative societies" (Norenzayan et al., 2016). This could illustrate an interesting case of how simple rules may contribute to the emergence of larger, more complex, social structures and normative rulesets. 
Similar reciprocal rules of thumb are found in early codes of law. For instance, the ancient Babylonian Code of Hammurabi (1755-1750 BC) - the best-preserved (but not first) law collection from the Ancient Near East - contains several reciprocal heuristics. Perhaps most famous is the "eye for an eye" law (code no. 196; in Slanski, 2012): "If a freeman has blinded the eye of another freeman, his eye shall be blinded." However, many "laws" follow the same heuristic if/then formula: if a man does $x$, then $y$ shall be done to him, where $y$ is often equivalent or identical to $x$ (Slanski, 2012, p. 104). Whilst the Code was not a legal code in the sense of contemporary prescribing laws, its rules and prescriptions were established by a sovereign authority and probably did describe real Babylonian legal practices (Slanski, 2012). It is also likely that the Code also had influence on the ideology of its time (ibid.). Such rules of thumb would therefore, at least to some extent, guide ancient legal decisions and therefore the behaviour of any legal subjects. Note also that heuristics are still used by many legal practitioners today (Gigerenzer \& Engel, 2006).

Rules of thumb also have guided, in the past and the present, the suite of moral inferences that guide our everyday judgment and decision-making. Although academic moral psychology (and philosophy) has traditionally focused more on analytical reasoning, evidence suggests that "moral judgment is more a matter of emotion and affective intuition than deliberate reasoning" (Greene \& Haidt, 2002). And typically, where intuition is found, so are heuristics and rules of thumb (Gigerenzer, 2007, 2015). Accordingly, we discuss in the following some examples of heuristic moral reasoning.

Cosmides and Tooby (2006) suggest that people often use moral heuristics which use cues related to the prevalence of luck to guide moral decisions and inferences. For instance, consider the following two claims (from Cosmides \& Tooby, 2006):

1. "If he is the victim of an unlucky tragedy, then we should pitch in to help him out."

2. "If he is the victim of an unlucky tragedy, then he does not deserve our help."

Cosmides and Tooby (2006) point out that whilst there is nothing logically faulty with statement 2., it likely seems awkward to the reader. Intuitively, we seem to follow a heuristic that reacts to 
unfortunate/unlucky outcomes with compassion. Cosmides and Tooby (ibid.) discuss why such a heuristic may have evolved: in a highly variable environment, luck plays a large role in success in activities such as hunting or foraging. However, in a variable environment, there is also reason to expect that the future will vary from the present, and that those who procured less food today may eventually be in a better position to reciprocate in the future. Therefore, helping someone with bad luck today can hedge against uncertainties in the future (by pooling resources with others), and thus provide fitness payoffs in the long term.

Similarly, Cosmides and Tooby (2006) argue that we use moral heuristics when we punish freeriders. Solving the free-rider problem is a key aspect in human cooperation, and one way to manage free-riding is to impose costs (i.e., punishments) on free-riders (Boyd et al., 2003, 2010). However, Cosmides and Tooby (2006) suggest that the punishing of free riders "does not result from a strategic rational analysis", since people often choose to pay to punish free-riders even in one-shot games (with no repetition). Instead, the decision rule we use for punishing free-riders "is more like a moral heuristic" that makes use of the limited inputs of 1 . one's personal level of contribution, 2. the average contribution level in the group, and 3. the level of contribution of each individual in the group. Such a heuristic could be formulated as: "more punitive sentiment is felt toward those who contribute less than the self as well as those who contribute less than the group average" (Cosmides \& Tooby, 2006). This is by no means the only possible heuristic to solve free-rider problems. Others include, e.g., heuristics related to frequency-dependent coordinated punishment (such as "choose to punish if a threshold of peers also signal willingness to punish"; see Boyd et al. (2010) for similar arguments).

Gigerenzer (2010) discusses moral heuristics in terms of "moral satisficing". For instance, it is welldocumented that there is higher prevalence of organ donation in countries where citizens are opted into organ donation by default, as compared to those countries where they are not (Johnson \& Goldstein, 2003). Gigerenzer (2010) suggests that there is a kind of moral heuristic at play here: "If there is a default, do nothing about it." Gigerenzer (2010, p. 539) suggests that a default bias may serve a prosocial function and facilitate the coordination of groups and cooperation: "Relying 
on defaults, specifically legal defaults, creates homogeneity within a society and thus helps cement it together."

Another case of a moral heuristic is the Tit-for-Tatrule (Gigerenzer, 2010, p. 546): "If you interact with another person and have the choice between being kind (cooperate) or nasty (defect), then: (a) be kind in the first encounter, thereafter (b) keep a memory of size one, and (c) imitate your partner's last behaviour (kind or nasty)." Although it is unlikely that humans would reliably follow such a strictly formalised version of reciprocal altruism, it has been suggested that soldiers on the frontlines of the First World War would have used a similar informal rule of thumb to guide smallunit level military behaviour. This is known as the "Live and Let Live" principle - refraining from offensive activity on the condition that this act of non-aggression is reciprocated (Ashworth, 1968, p. 411; 1980, p. 19).

Finally, Sunstein (2005) argues that "moral heuristics" play a pervasive role in moral, political, and legal judgments. One such heuristic Sunstein discusses is the "cold-heart heuristic" (Sunstein, 2005; based on Viscusi, 1999): Those who knowingly cause a death, but do so anyway, are regarded as cold-hearted, whilst those who remain ignorant about their actions' consequences are not.

The cold-heart heuristic is part of a broader category of act-omission heuristics, or moral heuristics that favour inaction over action. For example, Sunstein (2005, p. 540) mentions how in US citizens "have a constitutional right to withdraw equipment that is necessary to keep them alive, but they have no constitutional right to physician-assisted suicide". Although heuristics like act-omission heuristics may often misfire (it is easy to imagine scenarios where ignorance has worse outcomes than maliciousness!), Sunstein (2005, p. 541) notes that such "heuristics generally point in the right direction", and that "to say the least, it is desirable for people to act on the basis of a moral heuristic that makes it extremely abhorrent to throw innocent people to their death." Whilst a simple heuristic may misfire in some cases, it may still often be better and more generalizable than a more fine-grained approach, which could misfire even more. 
Altogether, the use of rules of thumb or heuristics in moral judgments and decision-making seems common, and together such heuristics serve the general purpose of facilitating the kind of prosocial interactions and reciprocity required for the emergence of complex large-scale human cultures. Gigerenzer (2010) points some future directions for research into moral heuristics: 1. Studying humans in social environments (since a moral rule of thumb may only work when it is reciprocated), 2. studying moral behaviour in everyday environments (because laboratory settings and hypothetical scenarios do away with the uncertainties that so pervasively characterize everyday experience), and 3. analysing observed behaviour in addition to verbal reports (since moral heuristics may be embedded in habits or tacit knowledge that people are not explicitly aware of). It is obvious that there is more to moral reasoning than heuristics alone - the point here is merely to suggest that moral heuristics can create simple scaffoldings and boundaries upon and within more complex patterns of human coordination and cooperation may emerge.

\section{Reliable ratios: rules of thumb in niche construction and technology}

Rules of thumb are, above all, practical rules. Therefore, it may be little surprise to find that rules of thumb have also been applied plentifully in the practical crafts and technical manufacture, guiding those broad aspects of human life that define cultural niche construction. Cultural niche construction (Laland et al., 2001; Laland \& O'Brien, 2011) refers to the aspects of cultural evolution where organisms shape their environments and the behavioural selective pressures within their ecological niches. Homo sapiens are, in many respects, the ultimate niche constructors or ecosystem engineers, having fitted most of their environments with various forms of infrastructures and technologies (Clark, 2015; Laland, 2018). Consequently, rules of thumb in these domains may have had a particularly large impact on the evolution of complex cultures.

Builders and innovators of the past (i.e., pre-modern or pre-industrial times) would often not have what we would today call scientific or even causal understanding of why their designs work, and they would often work without detailed plans (Fitchen, 1989). This is the case even with complex 
structures like $12^{\text {th }}$ to $13^{\text {th }}$ century Gothic cathedrals (James, 1982; Turnbull, 1993) or ancient Mediterranean ships (Olaberria, 2014). Rather, builders would learn through practical experience, trial and error, and tradition. The successful forms of techniques would survive and be copied by and taught to others, facilitated by elaborate social structures such as master-apprentice relations and guilds (Fitchen, 1989; Turnbull, 1993).

As recent discussion in cultural evolution and technology studies has emphasized, traditionally the main three sources of innovation have been recombination, incremental improvement and serendipity (Muthukrishna \& Henrich, 2016; Arthur, 2009). Cazzolla Gatti et al. (2020) appropriately call humans Homo tinkerus, since technology evolves when "tinkering humans cobble together" existing elements of technologies and rules. Shipbuilders as late as the $17^{\text {th }}$ century would have relatively little theoretical understanding of why ships worked; rather, practical rules for building had been passed on through generations of tinkering with the more successful forms surviving (West, 2017). Some notable cases illustrate how this lack of causal understanding or modelling resulted in failure, such as the infamous $17^{\text {th }}$ century Swedish warship Vasa presently on display in Stockholm - the ship, designed under hubristic royal ambitions, had much too much weight in the upper structure of its hull and sank on its maiden voyage (Cederlund, 2006).

Overall, however, the history of building and technology is much less bleak. Histories of engineering and building suggest that the practical knowledge used before mechanization made efficient use of cognitive shortcuts, and that rules of thumb often guided successful tinkering that led to technological innovation and more complex rules (Dhoop \& Olaberria, 2015; Fitchen, 1989; James, 1982; Olaberria, 2014; Turnbull, 1993). As Brencich \& Morbiducci (2007) note, ancient structures were designed often with "semi-empirical rules based on few simplified mechanical principles", but nevertheless, their structural performance in the majority of cases was surprisingly good. Whilst pre-modern builders wouldn't have scientific understanding, they would still have some simpler rules to help in problem-solving, and these rules would serve as the "mnemonics of the industry, being the only way that experience can be memorised and taught" (James, 1982, p. 32). 
For one interesting example, Crumlin-Pedersen $(1986,2009)$ suggests that Viking ships (such as the elaborate $9^{\text {th }}$ century Oseberg ship, Fig. 3) may have been designed partly by utilising rules of thumb. Certainly, Crumlin-Pedersen (1986, p. 220) emphasises, there are no indications that construction drawings or downscaled models (or perhaps even moulds) were used in Viking shipbuilding in Scandinavia. Shipbuilders would often be illiterate, and would not have understood the mechanical principles underlying the function of ships (Dhoop \& Olaberria, 2015). Instead, shipbuilders would construct ships "by eye, in a shell-first manner, and using rules of thumb to control the three-dimensional shape" (Dhoop \& Olaberria, 2015, p. 95). Rules of thumb could make use of simple geometric ratios. For example, the shape of the stem of ships like the $11^{\text {th }}$ century Skuldelev 3 was likely determined by simple geometrical proportions of the keel length (Crumlin-Pedersen, 2009, p. 153).

These proportional rules of thumb could be offloaded onto a simple physical form, for example as a story-stick on which critical measurements would be recorded (Dhoop \& Olaberria, 2015). In simpler cases, rules of thumb could be transcribed into a verbal form - less precise, but an effective memory aid and a pragmatic unit for cultural transmission (Dhoop \& Olaberria, 2015). Dhoop \& Olaberria $(2015$, p. 103) emphasize that the aim of these rules of thumb was not to rigidly define the construction of the ship. Rather, the builder would follow them as rough guidelines, maintaining the liberty to implement small adjustments wherever deemed necessary.

Some of these rules of thumb have survived to modern times in clinker building traditions. An excerpt from Crumlin-Pedersen (2009, p. 150) is worth quoting in detail:

"Within traditional clinker building communities, there is no indication of the use of drawings or advanced calculations for the design and construction of these ancient vessels or for their descendants until modern times, when some influence from the larger shipyards can be traced. Instead, rules-of-thumb and building-by-eye were the key words to the process. Today these terms are disregarded and held up to ridicule, but they are, nonetheless, the clue to the successful original construction of highly admired and beautiful vessels such as the Oseberg and Gokstad ships or the swift and powerful Viking longships.” 
Olaberria (2014, p. 353) discusses a very similar case in ancient Mediterranean shipbuilding, noting how "the knowledge accumulated by pre-scientific shipwrights could be transmitted by rules-of-thumb and practical procedures". Again, simple geometrical proportions may have been used to aid in ship construction. For example, with the $2^{\text {nd }}$ century CE Laurons-2, "the diameter of the curve of the sternpost is one-and-a-half times the diameter of the circle circumscribing the master-section, or equal to the length of the keel" (Olaberria, 2014, p. 356).

Figure 3. The well-preserved Oseberg ship, a $9^{\text {th }}$ century Viking clinker-built longship at display in Viking Ship Museum, Oslo. The ship is mainly oak and elaborately decorated. Fully manned, the ship could carry 30 oarsmen (Museum of Cultural History, 2021). Photo by Mikael A. Manninen.

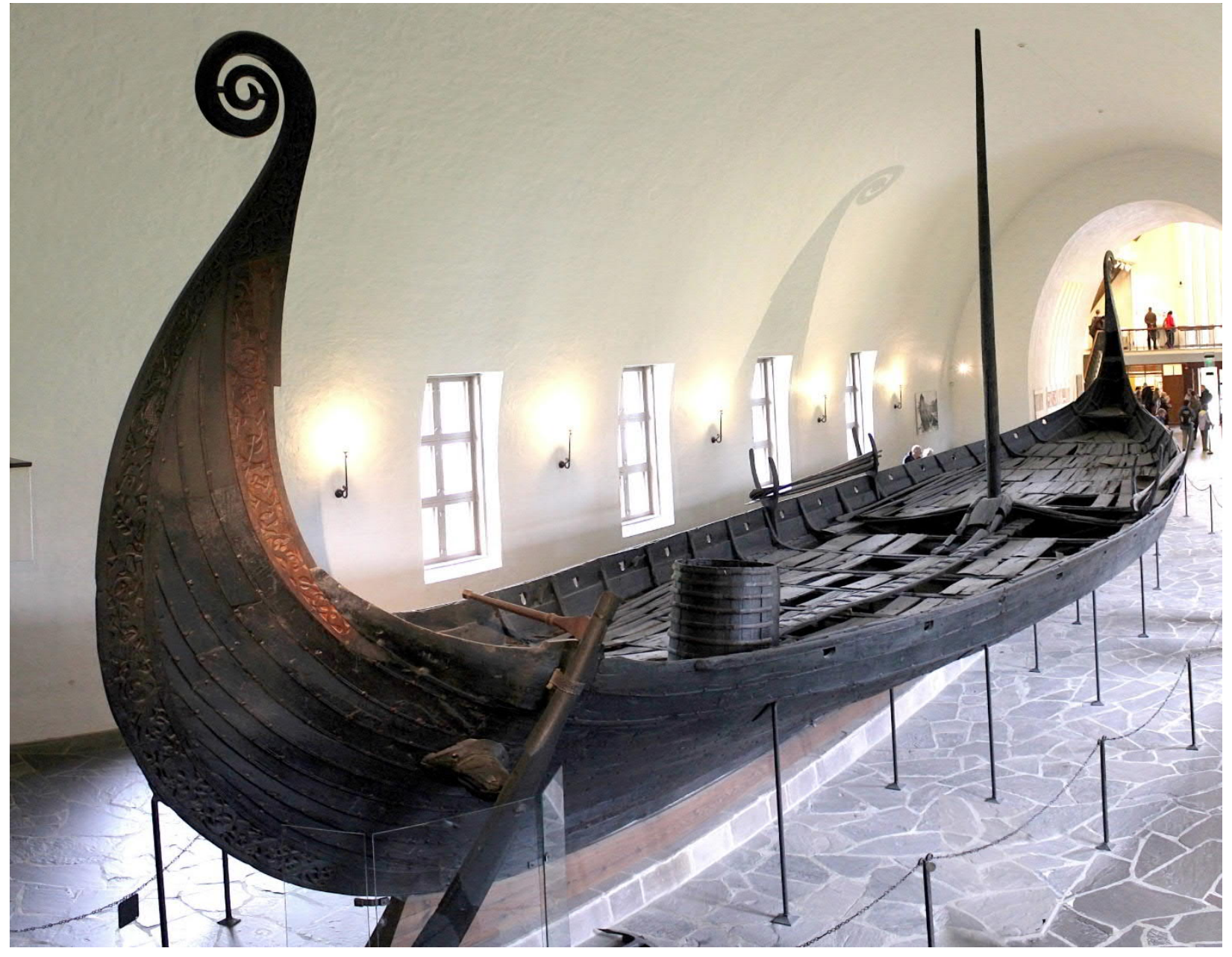


Although these rules of thumb may seem slightly more complex than others discussed in this article - at least to those among us with little experience in shipbuilding - they would be intuitive for a practitioner and simple enough to measure with tools no more complex than chalk lines and a pair of compasses. Simple proportional rules like these would be conveniently and accurately transmitted among shipbuilder communities and master-apprenticeship relations (Olaberria, 2014). These rules would be transmitted through practice rather than literature or explicit codes since builders would often be illiterate and uneducated in mathematics. The skills necessary for using these rules would have been “frozen' around practical design procedures using geometry and simple design tools" (Olaberria, 2014, p. 361). The rules would generally result in adequate and satisfactory results - a sort of pre-modern case of satisficing (Olaberria, 2014, p. 362).

Finnish blacksmith traditions (Rytkönen, 1931, pp. 143-146) are also reported to have made ample use of proportional rules of thumb. For example, when forging a scythe, the length of the required iron and steel bars would be one half of the length of the intended scythe blade. Various visual analogies were also used to decide the appropriate amount of heating during the quenching of different kinds of steel. For instance, one kind of steel would be heated until white, and another until it is the colour of a "ripe cranberry" (ibid; see also Brand et al., 2021 for discussion on the role of analogies as a catalyst for cultural evolution).

Other examples regarding the use of ratio-based rules of thumb in are evident in Greenlandic traditions in kayak construction. As Jensen (1975) writes, a well-tempered kayak must be "tailormade" for the kayaker. This is particularly important, since piloting a kayak requires the feeling of "being a part of" the kayak, which in turn requires a sufficiently tight fit as well as good positioning of the kayaker's body and legs (Bisceglio, 2013). Accordingly, subjective and variable bodily ratios (anthropometrics) are used in kayak construction. No drawings or fully standardised measurements are used, and the dimensions of the kayak vary with the bodily ratios of the kayaker. For example, in West-Greenlandic traditions, "the total length of the kayak should be approximately 3 times the height of the kayaker" (Petersen, 1981). Alternatively, the measure of 3 times the arm span (an 
arm span is typically near equivalent to height) may be used (Kayak Ways, 2021). Other rules of thumb include adding the arm span to the cubit (the length of the forearm from the tip of the middle finger to the elbow) to determine the length of a double-bladed paddle (Kayak Ways, 2021).

Southwest Alaskan Yup'ik people also have extensive traditions in using anthropometric measures for kayak construction (Lipka et al., 2010). This is evident in Yup'ik vocabulary, which includes concepts for the "length of outstretched arms from fingertips (yagneq), the length from fist to armpit (tallim cuqii), the length from middle of body to end of fingertips (taluyaneq), the distance of two elbow lengths (ikuyegarnerek malruk) made by putting the fists together", as well as the length from elbow to the end of the fist (ikuyegarneq) (Lipka et al., 2010, pp. 24 and 39). These measures could be used to construct a custom-sized kayak as follows (depicted in Figure 4): the kayak's total length would be two yagneq plus one tallim cuqii plus one taluyaneq (this includes the length of the cockpit, one tallim cuqii). The kayak's height at the cockpit would be one ikuyegarneq, and its width one ikuyegarnerek malruk.

Figure 4. Bodily proportions for kayak construction as used by the Yup'ik, based on information provided in Lipka et al. (2010). Background image is a profile of a Yup'ik hunting kayak, for rough reference. Kayak image source: Wikimedia commons, public domain (original source Nelson, 1900).

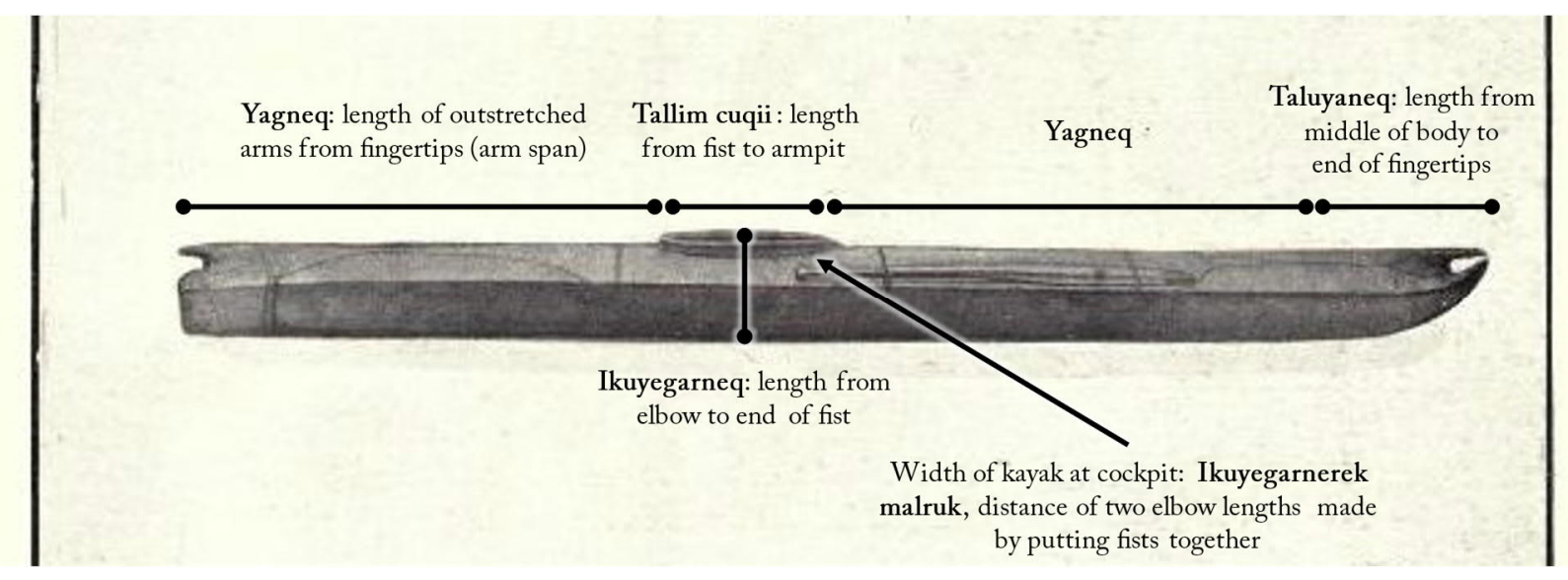


Rules of thumb have also been used in the construction of various other technological artefacts. Some evidence of these has been preserved in biographies of Ishi, the last known member of the Native American Yahi people (following the California Genocide). Pope (1920, p. 187) describes how Ishi's measurements for Yahi bow construction "were made according to some dimension of his body, such as a palm's breadth, the length of his arm, etc.” More specifically, Kroeber (1961, p. 190) describes how Ishi used bodily ratios in bow design: ${ }^{11}$

"Ishi fashioned a bow to the person who was to shoot it: there must be a certain proportion between the height of the archer and the length of his bow, and between the size of his hand and the thickness of his bow. The bow's length was the distance from the right hip joint to the left finger tips, measured with the person standing erect and extending the left arm forward in a straight line from the shoulder - a distance of four feet and two inches for Ishi. The greatest width and thickness of the bow is at either side of the hand grip. The width should be that of four fingers for a powerful bow; three fingers for a light hunting bow."

Pope (1918, p. 110) also describes how Ishi used auditory cues to determine a bow's quality:

"A good bow was one whose string made a high musical note when tapped with an arrow or snapped with the fingers. It should sing the note tin, tin, tin. This was the chief's bow. One whose note was dead and unmusical, Ishi treated with contempt.”

11 Kroeber's description is partly adapted from Pope's (Pope, 1918, pp. 106 \& 115) descriptions, which similarly follow: "[Ishi's] standard of measurement for a good bow was to hold a stave diagonally across his chest with one end in his right hand at the hip, and the left arm extended straight out at an angle of 45 degrees from the horizontal. The distance between these points was the proper length for a bow. This measured in his own case four feet and two inches. The width of the bow at the middle of each limb was three or four fingers, according to whether a light hunting bow or a powerful war bow was wanted." [... "The arrow in the condition just described was now accurately cut to a certain length. His method of measurement was to hold the butt against his own sternal notch and then, reaching along the shaft with his left hand, almost in his shooting position (as described below), he cut the shaft off at the end of his left forefinger." 
The use of anthropometric rules of thumb, such as in the cases of bow or kayak construction above, has the obvious benefit of not requiring external tools for measurement. Since we always carry our bodies around with us, a bodily unit of measure is a tremendously adaptive tool. Therefore, the use of body-proportions as units of measure offers highly mobile populations with tools and designs that are accurate and functional without the extra weight of specialized measuring tools. This is an important point of emphasis when considering the role rules of thumb may have had in prehistoric cultural evolution. After all, user-specific body-proportional units such as the foot or the cubit were predecessors of standardised units of measure such as the "royal cubit" of Old Kingdom Egypt $(2,700 \mathrm{BCE})$, the first known standardised measurement unit in human history (Stone, 2014).

Similar uses of rules of thumb have been documented in early Medieval church construction. Whilst the builders of exquisite Gothic cathedrals such as Chartres would not have detailed construction plans, models, or even universal units of measurement (e.g., masonry traditions had idiosyncratic measures of a foot), they would have access to simpler but efficient understanding of geometry that served as rules of thumb for design (James, 1982; Turnbull, 1993). Rules of thumb could, for example, make use of simple proportions or ratios: "half the number of feet in a span expressed in inches plus one inch will give the depth of a hardwood joist" (Turnbull, 1993, p. 323; based on James, 1979).

Likewise, the wall thickness of the Saxon church of Bradford-on-Avon might have been determined by a simple rule, using only a square and circle for measurement (James, 1982, p. 33; see Fig. 5 for details). Such simple rules would afford easy building with simple technologies, such as a pair of compasses, a straightedge, ruler, and string, and could be conveniently passed on from master to apprentice during the practice of construction (James, 1982; Turnbull, 1993). James (1982, p. 33-34) emphases that the kind of geometrical understanding used for building the 
cathedral at Chartres was not theoretical (contra, for example, Euclidean geometry), but thoroughly practical, enabling transmission with precision. ${ }^{12}$ Turnbull (1993, p. 323) elaborates:

"This sort of geometry is extremely powerful. It enables the transportation and transmission of structural experience, it makes possible the successful replication of a specific arrangement in different places and different circumstances, it reduces a wide variety of problems to a comparatively compact series of solutions, and it allows for a flexible rather than rigidly rule-bound response to differing problems.”

Figure 5. A simple rule from around the year $1000 \mathrm{CE}$ used to determine wall thickness at the Saxon church of Bradford-on-Avon (adapted from James, 1982, p. 33): "A square would be drawn inside the walls of the nave ["Interior"] and, to calculate the outside, a circle would be set around the square". The width of the leftover of the circle (pictured grey) would determine the thickness of the wall, as designated by the dashed lines. James (ibid.) emphasises that this heuristic would only work for relatively small buildings.

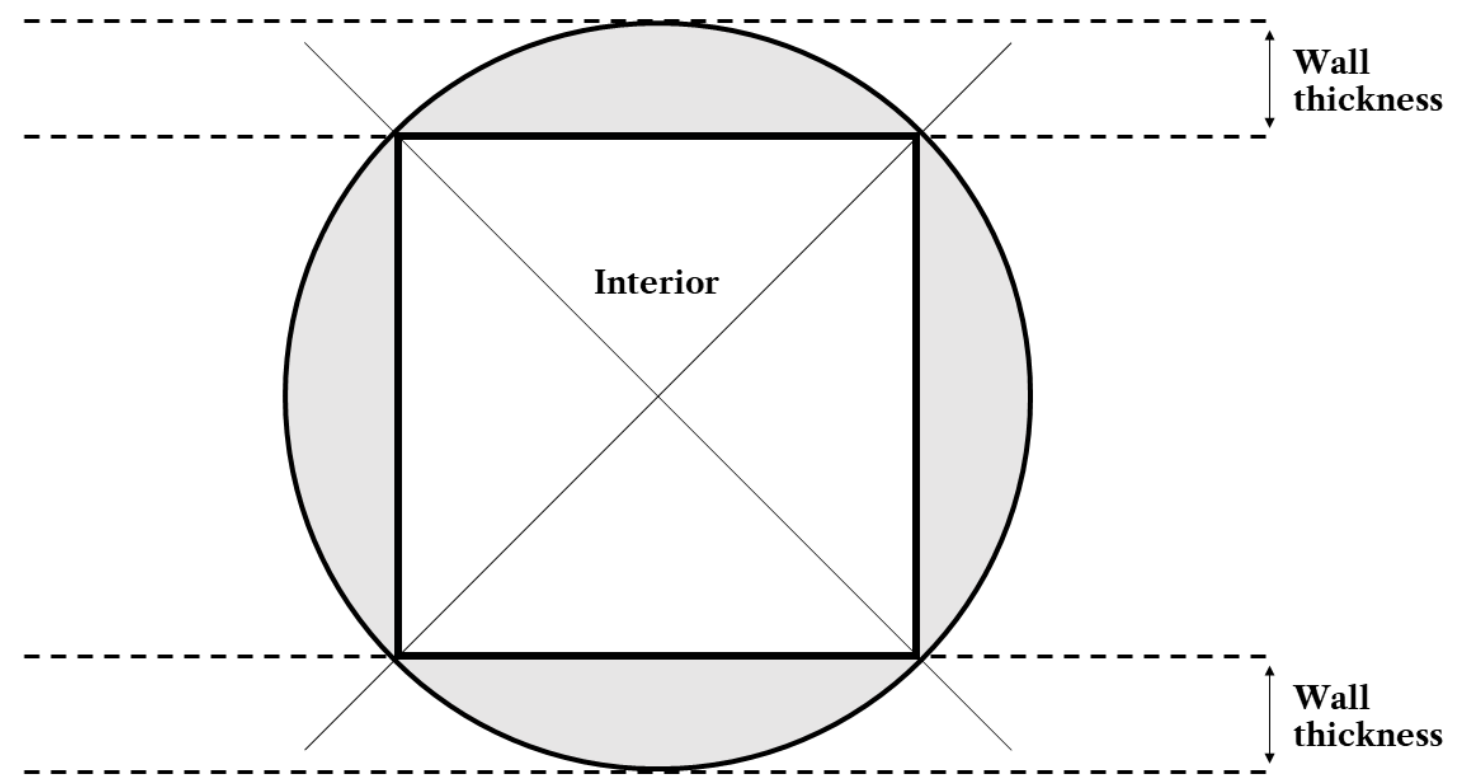

\footnotetext{
${ }^{12}$ It should be noted, however, that much of the geometry used to build Chartres was elaborate and certainly drew on well-established traditions with mathematical and religious influences. See particularly Chapter 9 in (James,
} 1982) for discussion. 
Again, worth reemphasizing is the notion that the use of rules of thumb does not imply incompetence or primitivity - rather, these rules of thumb were elaborate practical cognitive gadgets that stood the test of time, and importantly, the test of waves, shocks, and erosion. Moreover, it is obvious that rules of thumb do not explain the whole of these complex practices. The rules of thumb used by shipbuilders, for example, would not replace but rather complement their artisanship and eye for working wood (Olaberria, 2014). Rather, rules of thumb should be thought of as important parts of our cognitive "adaptive toolbox" (Gigerenzer \& Todd, 1999a) useful tools that help in the construction of complex structures.

As contemporary architects and urban theorists such as Christopher Alexander $(1977,1979)$ and Jane Jacobs (1961) have emphasised, even the most complex urban environments are ultimately built upon simple components, social interactions and patterns (Mehaffy, 2017). Equally, it is easy to imagine how practical shipbuilding heuristics enabled the expansion of complex Viking or Mediterranean trade networks, how rules of thumb for kayak construction afforded successful hunting expeditions, how variable anthropometrics evolved into standardised units of measure, or how simple rules in church construction helped form the basis for the rich cultural and social interactions that took place within and around Gothic cathedrals.

Here, rules of thumb may act as catalysts that twist the so-called cultural ratchet (Tennie et al., 2009), creating new affordances (or “adjacent possible opportunities") for the evolution of cumulative cultures (Cazzolla Gatti et al., 2020). This also applies to rules of thumb themselves: as James (1982, p. 33) notes, the number and complexity of rules in Medieval construction had to be increased when architecture developed in complexity - successful simple rules may evolve into more complex order (recall Gall's law above). Simple rules may ultimately contribute to the combinatorial explosion of human creativity, where novelty begets novelty (Cazzolla Gatti et al., 2020; Arthur, 2009).

Unfortunately, as practical crafts became increasingly mechanised - and as a direct result of scientific management trends such as Taylorism, which sought to replace diverse and idiosyncratic 
rules of thumb with standardised practices ${ }^{13}$ (Scott, 1998; Taylor, 1919) - many traditional rules of thumb used in practical crafts and architecture did not survive to the modern day. Uncovering traditional rules of thumb on the basis of archaeological, architectural or ethnographic evidence is difficult and tedious work which often requires deep expertise in the studied practice (see, e.g., Crumlin-Pedersen, 1986, 2009; Dhoop \& Olaberria, 2015; Fitchen, 1989; James, 1982; Olaberria, 2014; Alexander, 1977). A systematic research program combining insights from ecological rationality and cultural evolution could begin the task of putting together the few examples of past rules of thumb we have reliable evidence of.

Meanwhile, further evidence of the usefulness of rules of thumb in design can be found in contemporary practices in design and architecture. One example could be the principle of designing public spaces to conform with the social field of vision. This is achieved by maintaining visual distances in public squares under 100 meters, so that a pedestrian can see activities across the whole plaza (Gehl, 2013). This is and has been common and traditional practice in the design of European public squares, where distances greater than 100 meter are rare and 80-90-meter lengths are much more common (Gehl, 2013). Christopher Alexander, an architect famous for studying recurrent patterns in architecture and cities, has also emphasised how simple rules of thumb may guide the design of lively and aesthetically pleasing environments. Alexander's rules of thumb include, for example, the following principles: "Balconies and porches that are less than six feet deep are hardly ever used"; "When they have a choice, people will always gravitate to those rooms that have light on two sides", and "Avoid designs that repeat more than nine elements at any one scale" (Alexander, 1977, 1979).

\footnotetext{
13 Taylor's (1919, Ch. 1) intention was, in his own words, "to show the enormous gains which would result from the substitution by our workmen of scientific for rule-of-thumb methods". In 1919, Taylor described rule of thumb methods as "inefficient" but still "almost universal in all trades, and in practicing which our workmen waste a large part of their effort." Rules of thumb, Taylor argued, should be replaced with standardised procedures, and with "the gradual substitution of science for rule of thumb throughout the mechanic arts". Ultimately, this would involve "a complete change in the mental attitude of all the men in the shop toward their work and toward their employers". For many, this meant the loss of traditional, idiosyncratic and artisanal modes of production (Scott, 1998).
} 


\section{Conclusion}

To conclude, we sum up the four key arguments presented in the introduction. Firstly, this paper has revealed some of human societies' rich history of applying rules of thumb in guiding their daily activities and social organization. Examples have been drawn from cases as variable as foraging, agriculture, shipbuilding, architecture, technology, social learning, law, religion, and moral judgments (among others).

Second, rules of thumb have been illustrated to be suitable vehicles for high-fidelity cultural transmission. As has been illustrated with many case studies, rules of thumb can conveniently be broken into accurately transmissible structures, and embedded into master-apprentice relations, artisan traditions, stories, analogies, material artefacts, and moral rules. Particularly in the latter case, heuristics may afford the kinds of prosocial interactions necessary for the evolution of complex cultures. The value of rules of thumb in pre-literate or pre-modern societies has also been highlighted, since prior to the widespread use of standardised measures, written language, and scientific/mathematical notation, other high-fidelity modes for transmission would have been required.

Third, rules of thumb have been shown to make efficient use of environmental structures and ecological validities. By utilising environmental features such as phenological events, rules of thumb can offload much of decision-making and cognitive effort to reliably recurring ecological phenomena. This is not a foolproof strategy, but particularly in stable ecological niches has proven to be adaptive. However, as ecological systems degrade, traditional rules of thumb may become redundant. Elsewhere, in technological domains of behaviour, such as ship or kayak construction and Medieval architecture, rules of thumb have made particularly efficient use of simple geometrical or bodily ratios, which may be taught and learned with considerable accuracy. The use

of anthropometric (body ratio-based) rules of thumb can also be particularly efficient since they may afford custom-tailored problem-solving that accommodates for interpersonal variation. 
Unlike other measurement tools, anthropometric measures also have the benefit of always being available, which may have been useful particularly for mobile populations such as hunter-gatherers.

Fourth, rules of thumb may provide simple building blocks and scaffoldings which may facilitate the development of more complex social interactions and rulesets. Simple rules for construction can evolve into more elaborate ones, heuristics may be used to organise complex cultural behaviours such as agricultural practices, variable bodily proportions may morph into standardised units of measure, and simple reciprocal heuristics may facilitate complex prosocial interactions. Moreover, in behaviours such as foraging, simple heuristics may serve as scaffoldings which designate safe and efficient boundaries for individual learning. Rules of thumb rarely work alone, and often work best when immersed in skilful practices and practical traditions. Therefore, they are best interpreted as complementary to other forms of knowing. As is so typical to complex systems, simple rules may play an important role in generating complex behaviours, and human cultures seem to be no exception.

Finally, we point to some avenues of further research. Research in cultural evolution and decisionmaking is can provide additional examples of how simple heuristics and rules of thumb have guided human adaptation and cultural behaviours. Examples can be drawn from ethnographic literature as well as from empirical studies. In addition, existing models of social learning, cultural niche construction, and other modes of cultural evolution can be complemented with rules of thumb and heuristic cognitive processes for increased realism. This is particularly promising, since many rules of thumb are conveniently formalised into algorithmic procedures (and thus amenable for, e.g., agent-based models). This could help to develop more plausible and realistic models of cultural evolution and human adaptation in the past and for the future (e.g., climate adaptation), and highlight how simple cognitive rules may contribute to the evolution of complex cultures. A better understanding of traditional rules of thumb may also help us understand the challenges of the Anthropocene. If many traditional rules of thumb have enabled us to "think with our environments" and adapt to our local ecological niches, how then may the radical ecosystem changes today and tomorrow endanger the fitness of traditional knowledge? 


\section{References}

Acerbi, A. (2019). Cultural Evolution in the Digital Age. Oxford University Press.

Alexander, C. (1977). A Pattern Language: Towns, Buildings, Construction. Oxford University Press.

Alexander, C. (1979). The Timeless Way of Building. Oxford University Press.

Arthur, W. B. (2009). The Nature of Technology: What It Is and How It Evolves. Simon and Schuster.

Arthur, W. B. (2021). Foundations of complexity economics. Nature Reviews Physics, 3(2), 136-145. https://doi.org/10.1038/s42254-020-00273-3

Ashworth, A. E. (1968). The sociology of trench warfare 1914-18. The British Journal of Sociology, 19(4), 407-423.

Ashworth, T. (1980). Trench Warfare 1914-1918: The Live and Let Live System. Macmillan.

Atran, S., \& Henrich, J. (2010). The evolution of religion: How cognitive by-products, adaptive learning heuristics, ritual displays, and group competition generate deep commitments to prosocial religions. Biological Theory, 5(1), 18-30.

Axelrod, R., \& Hamilton, W. D. (1981). The evolution of cooperation. Science, 211(4489), 1390-1396. https://doi.org/10.1126/science.7466396

Barnosky, A. D., Hadly, E. A., Bascompte, J., Berlow, E. L., Brown, J. H., Fortelius, M., Getz, W. M., Harte, J., Hastings, A., Marquet, P. A., Martinez, N. D., Mooers, A., Roopnarine, P., Vermeij, G., Williams, J. W., Gillespie, R., Kitzes, J., Marshall, C., Matzke, N., ... Smith, A. B. (2012). Approaching a state shift in Earth's biosphere. Nature, 486(7401), 52-58. https://doi.org/10.1038/nature11018

Barnosky, A., \& Hadly, E. (2015). End Game: Tipping Point for Planet Earth? Harpercollins Publishers. http://www.harpercollins.co.nz/9780007548163/end-game-tipping-point-for-planet-earth

Barrett, L. (2011). Beyond the Brain: How Body and Environment Shape Animal and Human Minds. Princeton University Press.

Begall, S., Červený, J., Neef, J., Vojtěch, O., \& Burda, H. (2008). Magnetic alignment in grazing and resting cattle and deer. Proceedings of the National Academy of Sciences, 105(36), 13451-13455. https://doi.org/10.1073/pnas.0803650105

Berretty, P. M., Todd, P. M., \& Martignon, L. (1999). Categorization by Elimination: Using few cues to choose. In G. Gigerenzer \& Todd, Peter M. (Eds.), Simple Heuristics That Make Us Smart (pp. 235-254). Oxford University Press.

Bisceglio, P. (2013). How to Build a Greenland Kayak from Scratch. Smithsonian Magazine. https://www.smithsonianmag.com/smithsonian-institution/how-to-build-a-greenland-kayak-fromscratch-976438/

Boyd, R., Gintis, H., \& Bowles, S. (2010). Coordinated punishment of defectors sustains cooperation and can proliferate when rare. Science, 328(5978), 617-620. https://doi.org/10.1126/science.1183665

Boyd, R., Gintis, H., Bowles, S., \& Richerson, P. J. (2003). The evolution of altruistic punishment. Proceedings of the National Academy of Sciences, 100(6), 3531-3535. https://doi.org/10.1073/pnas.0630443100

Brand, C. O., Mesoudi, A., \& Smaldino, P. E. (2021). Analogy as a catalyst for cumulative cultural evolution. Trends in Cognitive Sciences, O(0). https://doi.org/10.1016/j.tics.2021.03.002

Brencich, A., \& Morbiducci, R. (2007). Masonry arches: Historical rules and modern mechanics. International Journal of Architectural Heritage, 1(2), 165-189. https://doi.org/10.1080/15583050701312926

Bullock, S., \& Todd, P. M. (1999). Made to measure: Ecological rationality in structured environments. Minds and Machines, 9(4), 497-541. https://doi.org/10.1023/A:1008352717581

Callebaut, W. (2007). Herbert Simon's silent revolution. Biological Theory, 2(1), 76-86. https://doi.org/10.1162/biot.2007.2.1.76

Cazzolla Gatti, R., Koppl, R., Fath, B. D., Kauffman, S., Hordijk, W., \& Ulanowicz, R. E. (2020). On the emergence of ecological and economic niches. Journal of Bioeconomics, 22, 99-127. 
Cederlund, C. O. (2006). Vasa I: The Archaeology of a Swedish Royal Ship of 1628. National Maritime Museum of Sweden.

Centola, D. (2018). How Behavior Spreads: The Science of Complex Contagions (Vol. 3). Princeton University Press.

Centola, D. (2021). Change: How to Make Big Things Happen. New York City, NY: Little, Brown and Company.

Chisholm Hatfield, S., Marino, E., Whyte, K. P., Dello, K. D., \& Mote, P. W. (2018). Indian time: Time, seasonality, and culture in Traditional Ecological Knowledge of climate change. Ecological Processes, 7(1), 25. https://doi.org/10.1186/s13717-018-0136-6

Clark, A. (2015). Surfing Uncertainty: Prediction, Action, and the Embodied Mind. Oxford University Press.

Clark, A., \& Chalmers, D. (1998). The extended mind. Analysis, 58(1), 7-19.

Colding, J., \& Folke, C. (2001). Social taboos: "Invisible" systems of local resource management and biological conservation. Ecological Applications, 11(2), 584-600. https://doi.org/10.1890/10510761(2001)011[0584:STISOL]2.0.CO;2

Connolly, K. (2015). Germany attributes spike in mushroom poisonings to foraging refugees. The Guardian. https://www.theguardian.com/world/2015/sep/29/germany-attributes-mushroompoisonings-foraging-refugees

Constant, A., Clark, A., Kirchhoff, M., \& Friston, K. J. (2019). Extended active inference: Constructing predictive cognition beyond skulls. Mind \& Language, $n / a(\mathrm{n} / \mathrm{a})$. https://doi.org/10.1111/mila.12330

Conway, J. (1970). The game of life. Scientific American, 223(4), 4.

Cosmides, L., \& Tooby, J. (2006). Evolutionary psychology, moral heuristics, and the law. In G. Gigerenzer \& C. Engel (Eds.), Heuristics and The Law (pp. 175-205). Dahlem University Press.

Crumlin-Pedersen, O. (1986). Aspects of Viking-age shipbuilding. Journal of Danish Archaeology, 5(1), 209-228. https://doi.org/10.1080/0108464X.1986.10589968

Crumlin-Pedersen, O. (2009). Boat and boat house: The conceptional origins of clinker boats and boatshaped halls of the fourth to eleventh centuries in Scandinavia. In H. Nowacki \& W. Lefèvre (Eds.), Creating Shapes in Civil and Naval Architecture (pp. 194-212). Brill.

Csikszentmihalyi, M. A. (2008). The golden rule in Confucianism. In J. Neusner \& B. D. Chilton (Eds.), The Golden Rule: The Ethics of Reciprocity in World Religions (pp. 157-169). Bloomsbury Publishing.

Czerlinski, J., Gigerenzer, G., \& Goldstein, D. G. (1999). How good are simple heuristics? In G. Gigerenzer \& P. M. Todd (Eds.), Simple Heuristics That Make Us Smart (pp. 97-118). Oxford University Press.

Davis, R. H. (2008). A Hindu Golden Rule, in context. In J. Neusner \& B. D. Chilton (Eds.), Golden Rule: The Ethics of Reciprocity in World Religions (pp. 146-156). Bloomsbury Publishing.

Dhoop, T., \& Olaberria, J.-P. (2015). Practical knowledge in the Viking Age: The use of mental templates in clinker shipbuilding. International Journal of Nautical Archaeology, 44(1), 95-110. https://doi.org/10.1111/1095-9270.12081

Eisenhardt, K. M., \& Sull, D. N. (2001). Strategy as simple rules. Harvard Business Review, 79(1), 106119.

Elävä perintö. (2019). Sienestys-wiki, Elävä perintö. https://wiki.aineetonkulttuuriperinto.fi/wiki/Sienestys

Fitchen, J. (1989). Building Construction Before Mechanization. MIT Press.

Fitchett, J. M., \& Ebhuoma, E. (2018). Phenological cues intrinsic in indigenous knowledge systems for forecasting seasonal climate in the Delta State of Nigeria. International Journal of Biometeorology, 62(6), 1115-1119. https://doi.org/10.1007/s00484-017-1495-x

Gall, J. (1975). General Systemantics: An Essay on how Systems Work, and Especially how They Fail. General Systemantics Press.

Gehl, J. (2013). Cities for People. Island Press. 
Gensler, H. J. (2013). Ethics and the Golden Rule. Routledge.

Gigerenzer, G. (2004). Fast and frugal heuristics: The tools of bounded rationality. In D. J. Koehler \& N. Harvey (Eds.), Blackwell Handbook of Judgment and Decision Making (pp. 62-88). Blackwell Publishing. https://doi.org/10.1002/9780470752937.ch4

Gigerenzer, G. (2007). Gut Feelings: The Intelligence of the Unconscious. Penguin.

Gigerenzer, G. (2008a). Why Heuristics Work. Perspectives on Psychological Science, 3(1), 20-29. https://doi.org/10.1111/j.1745-6916.2008.00058.x

Gigerenzer, G. (2008b). Rationality for Mortals: How People Cope with Uncertainty. Oxford University Press.

Gigerenzer, G. (2010). Moral satisficing: Rethinking moral behavior as bounded rationality. Topics in Cognitive Science, 2(3), 528-554.

Gigerenzer, G. (2015). Risk Savvy: How to Make Good Decisions. Penguin.

Gigerenzer, G. (2018). The bias bias in behavioral economics. Review of Behavioral Economics, 5(3-4), 303-336.

Gigerenzer, G., \& Engel, C. (2006). Heuristics and the Law. MIT Press.

Gigerenzer, G., \& Kurzenhaeuser, S. (2005). Fast and frugal heuristics in medical decision making. In R. Bibace, J. Valsiner, J. Laird, \& K. Noller (Eds.), Science and Medicine in Dialogue: Thinking Through Particulars and Universals (pp. 3-15). Praeger Westport, CT.

Gigerenzer, G., \& Todd, P. M. (1999a). Fast and frugal heuristics: The adaptive toolbox. In G. Gigerenzer \& P. M. Todd (Eds.), Simple Heuristics That Make Us Smart (pp. 3-34). Oxford University Press.

Gigerenzer, G., \& Todd, P. M. (1999b). Simple Heuristics That Make Us Smart. Oxford University Press.

Goldstein, D. G., \& Gigerenzer, G. (2002). Models of ecological rationality: The recognition heuristic. Psychological Review, 109(1), 75. https://doi.org/10.1037//0033-295X.109.1.75

Goldstein, D. G., \& Gigerenzer, G. (2008). The Recognition Heuristic and the Less-Is-More Effect. In C. R. Plott \& V. L. Smith (Eds.), Handbook of Experimental Economics Results (Vol. 1, pp. $987-$ 992). Elsevier. https://doi.org/10.1016/S1574-0722(07)00106-0

Green, W. S. (2008a). Parsing reciprocity: Questions for the golden rule. In J. Neusner \& B. D. Chilton (Eds.), The Golden Rule: The Ethics of Reciprocity in World Religions (pp. 1-8). Bloomsbury Publishing.

Green, W. S. (2008b). "Wired for Reciprocity": Some Concluding Reflections. In J. Neusner \& B. D. Chilton (Eds.), The Golden Rule: The Ethics of Reciprocity in World Religions (pp. 170-171). Bloomsbury Publishing.

Greene, J., \& Haidt, J. (2002). How (and where) does moral judgment work? Trends in Cognitive Sciences, 6(12), 517-523. https://doi.org/10.1016/S1364-6613(02)02011-9

Haines, R. (2017). Use of Traditional Phenological Knowledge Indicators to Predict Lake Sturgeon Spawning Timing on the Seine River (International Joint Commission).

Hammond, K. R. (1998). Ecological validity: Then and now. Unpublished Manuscript Available Electronically at: Https://Www.Albany.Edu/Cpr/Brunswik/Notes/Essay2.Html.

Haselton, M. G., Bryant, G. A., Wilke, A., Frederick, D. A., Galperin, A., Frankenhuis, W. E., \& Moore, T. (2009). Adaptive Rationality: An Evolutionary Perspective on Cognitive Bias. Social Cognition, 27(5), 733-763. https://doi.org/10.1521/soco.2009.27.5.733

Henrich, J. (2015). The Secret of our Success: How Culture is Driving Human Evolution, Domesticating our Species, and Making us Smarter. Princeton University Press.

Henrich, J., \& Boyd, R. (1998). The evolution of conformist transmission and the emergence of betweengroup differences. Evolution and Human Behavior, 19(4), 215-241. https://doi.org/10.1016/S1090-5138(98)00018-X

Henrich, J., Boyd, R., Bowles, S., Camerer, C., Fehr, E., Gintis, H., \& McElreath, R. (2001). In search of homo economicus: Behavioral experiments in 15 small-scale societies. American Economic Review, 91(2), 73-78. 
Henrich, J., \& Gil-White, F. J. (2001). The evolution of prestige: Freely conferred deference as a mechanism for enhancing the benefits of cultural transmission. Evolution and Human Behavior, 22(3), 165-196. https://doi.org/10.1016/S1090-5138(00)00071-4

Henrich, J., \& Henrich, N. (2010). The evolution of cultural adaptations: Fijian food taboos protect against dangerous marine toxins. Proceedings of the Royal Society B: Biological Sciences, 277(1701), 3715-3724.

Henrich, N., \& Henrich, J. P. (2007). Why Humans Cooperate: A Cultural and Evolutionary Explanation. Oxford University Press.

Heyes, C. (2018). Cognitive Gadgets: The Cultural Evolution of Thinking. Harvard University Press.

Heyes, C. (2019). Précis of cognitive gadgets: The cultural evolution of thinking. Behavioral and Brain Sciences, 42. https://doi.org/10.1017/S0140525X18002145

Hoppitt, W., \& Laland, K. N. (2013). Social Learning: An Introduction to Mechanisms, Methods, and Models. Princeton University Press.

Hutchinson, J. M. C., \& Gigerenzer, G. (2005). Simple heuristics and rules of thumb: Where psychologists and behavioural biologists might meet. Behavioural Processes, 69(2), 97-124. https://doi.org/10.1016/j.beproc.2005.02.019

Ingold, T. (1996). The optimal forager and economic man. Nature and Society: Anthropological Perspectives, 25-44.

Jacobs, J. (1961). The Death and Life of Great American Cities. Random House.

James, J. (1979). The Contractors of Chartres. Mandorla.

James, J. (1982). Chartres: The Masons Who Built a Legend. Routledge \& Kegan Paul.

Jensen, P. S. (1975). The Greenland Kayak and its Accessories. Copenhagen: Nyt Nordisk Forlag.

Jiménez, Á. V., \& Mesoudi, A. (2019). Prestige-biased social learning: Current evidence and outstanding questions. Palgrave Communications, 5(1), 1-12. https://doi.org/10.1057/s41599-019-0228-7

Johnson, D. D. P., Blumstein, D. T., Fowler, J. H., \& Haselton, M. G. (2013). The evolution of error: Error management, cognitive constraints, and adaptive decision-making biases. Trends in Ecology \& Evolution, 28(8), 474-481. https://doi.org/10.1016/j.tree.2013.05.014

Johnson, E. J., \& Goldstein, D. (2003). Do defaults save lives? Science, 302(5649), 1338-1339. https://doi.org/10.1126/science.1091721

Kaaronen, R. O. (2019). The art of mushroom foraging: A phenomenological inquiry. In The Side View Journal (pp. 22-26). The Side View Press. https://thesideview.co/articles/the-art-of-mushroomforaging/

Kaaronen, R. O. (2020a). Mycological rationality: Heuristics, perception and decision-making in mushroom foraging. Judgment and Decision Making, 15(5). https://doi.org/10.31234/osf.io/7g8er

Kaaronen, R. O. (2020b). Steps to a Sustainable Mind: Explorations into the Ecology of Mind and Behaviour. Publications of the Faculty of Social Sciences, University of Helsinki.

Kaaronen, R. O., Manninen, M. A., Roe, E., Hukkinen, J. I., \& Eronen, J. T. (2021). Lessons for human survival in a world without ecological templates: What can we learn from small-scale societies? Ecology and Society, 26(3).

Kahneman, D. (2011). Thinking, Fast and Slow. Macmillan.

Kauffman, S. A. (2008). Reinventing the Sacred: A New View of Science, Reason, and Religion. Hachette UK.

Kauffman, S. A. (2019). A World Beyond Physics: The Emergence and Evolution of Life. Oxford University Press.

Kaukonen, T.-I. (1946). Pellavan ja hampun viljely ja muokkaus Suomessa. Kansatieteellinen tutkimus. Suomen muinaismuistoyhdistys.

Kay, J. A., \& King, M. A. (2020). Radical Uncertainty: Decision-Making for an Unknowable Future. Bridge Street Press.

Kayak Ways. (2021). Qajaq Fitting - KAYAK WAYS. https://kayakways.net/kayaks/qajaq/qajaq-fitting/ 
Kendal, J., Giraldeau, L.-A., \& Laland, K. (2009). The evolution of social learning rules: Payoff-biased and frequency-dependent biased transmission. Journal of Theoretical Biology, 260(2), 210-219. https://doi.org/10.1016/j.jtbi.2009.05.029

Kozyreva, A., \& Hertwig, R. (2019). The interpretation of uncertainty in ecological rationality. Synthese. https://doi.org/10.1007/s11229-019-02140-w

Laine, Y. (1944). Sotilaan puhdetyöopas. Propaganda-aseveljet R.Y.

Laland, K. N. (2018). Darwin's Unfinished Symphony: How Culture Made the Human Mind. Princeton University Press.

Laland, K. N., \& O’Brien, M. J. (2011). Cultural niche construction: An introduction. Biological Theory, $6(3), 191-202$.

Laland, K. N., Odling-Smee, J., \& Feldman, M. W. (2001). Cultural niche construction and human evolution. Journal of Evolutionary Biology, 14(1), 22-33.

Lansing, J. S. (1987). Balinese "Water Temples" and the Management of Irrigation. American Anthropologist, 89(2), 326-341.

Lansing, J. S. (2006). Perfect Order: Recognizing Complexity in Bali. Princeton University Press.

Lantz, T. C., \& Turner, N. J. (2003). Traditional phenological knowledge of Aboriginal peoples in British Columbia. Journal of Ethnobiology, 23(2), 263-286.

Lipka, J., Jones, C., Gilsdorf, N., Remick, K., \& Rickard, A. (2010). Kayak Design: Scientific Method and Statistical Analysis (Part of the series Math in a Cultural Context: Lessons Learned from Yup'ik Eskimo Elders). Calgary: Detselig.

Malafouris, L. (2013). How Things Shape the Mind. MIT press.

Marewski, J. N., Gaissmaier, W., \& Gigerenzer, G. (2010). Good judgments do not require complex cognition. Cognitive Processing, 11(2), 103-121. https://doi.org/10.1007/s10339-009-0337-0

Martignon, L., Katsikopoulos, K. V., \& Woike, J. K. (2008). Categorization with limited resources: A family of simple heuristics. Journal of Mathematical Psychology, 52(6), 352-361. https://doi.org/10.1016/j.jmp.2008.04.003

Martin, G. (2021). 'Rule of thumb'-The meaning and origin of this phrase. Phrasefinder. https://www.phrases.org.uk/meanings/rule-of-thumb.html

Mehaffy, M. W. (2017). Cities Alive: Jane Jacobs, Christopher Alexander, and the Roots of the New Urban Renaissance. Sustasis Press.

Mesoudi, A. (2011). Cultural Evolution. University of Chicago Press.

Ministry of the Environment. (2019). Everyman's rights. https://www.ymparisto.fi/enUS/Nature/Everymans_rights(27721)

Mitchell, M. (2009). Complexity: A Guided Tour. Oxford University Press.

Moazami, M. (2008). The Golden Rule in Zoroastrianism. In J. Neusner \& B. D. Chilton (Eds.), The Golden Rule: The Ethics of Reciprocity in World Religions (pp. 65-75). Bloomsbury Publishing.

Museum of Cultural History. (2021). The Oseberg ship - an elegant vessel. https://www.khm.uio.no/english/visit-us/viking-ship-museum/exhibitions/oseberg/an-elegantvessel/index.html

Muthukrishna, M., \& Henrich, J. (2016). Innovation in the collective brain. Philosophical Transactions of the Royal Society B: Biological Sciences, 371(1690), 20150192. https://doi.org/10.1098/rstb.2015.0192

Nelson, E. W. (1900). The Eskimo about Bering Strait. US Government Printing Office.

Neusner, J., \& Chilton, B. D. (2008). The Golden Rule: The Ethics of Reciprocity in World Religions. Bloomsbury Publishing.

Norenzayan, A., Atran, S., Faulkner, J., \& Schaller, M. (2006). Memory and mystery: The cultural selection of minimally counterintuitive narratives. Cognitive Science, 30(3), 531-553. https://doi.org/10.1207/s15516709cog0000_68

Norenzayan, A., Shariff, A. F., Gervais, W. M., Willard, A. K., McNamara, R. A., Slingerland, E., \& Henrich, J. (2016). The cultural evolution of prosocial religions. Behavioral and Brain Sciences, 39. 
OED Online. (2021). Rule of thumb, n. And adj. In OED Online. Oxford University Press. https://www.oed.com/view/Entry/168726

Olaberria, J.-P. (2014). The conception of hull shape by shell-builders in the Ancient Mediterranean. International Journal of Nautical Archaeology, 43(2), 351-368. https://doi.org/10.1111/10959270.12068

Pacheco-Cobos, L., Winterhalder, B., Cuatianquiz-Lima, C., Rosetti, M. F., Hudson, R., \& Ross, C. T. (2019). Nahua mushroom gatherers use area-restricted search strategies that conform to marginal value theorem predictions. Proceedings of the National Academy of Sciences, 116(21), 1033910347.

Petersen, H. C. (1981). Qaanniornermut ilitsersuut. Greenland National Museum \& Archives and Atuakkiorfik/Greenland.

Polanyi, M. (1969). Knowing and Being: Essays. University of Chicago Press.

Polanyi, M. (1974). Personal Knowledge: Towards a Post-Critical Philosophy. University of Chicago Press.

Polanyi, M. (2009). The Tacit Dimension. University of Chicago Press.

Prober, S., O'Connor, M., \& Walsh, F. (2011). Australian Aboriginal peoples' seasonal knowledge: A potential basis for shared understanding in environmental management. Ecology and Society, 16(2). https://doi.org/10.5751/ES-04023-160212

Retnowati, A., Anantasari, E., Marfai, M. A., \& Dittmann, A. (2014). Environmental ethics in local knowledge responding to climate change: An understanding of seasonal traditional calendar PranotoMongso and its phenology in Karst Area of GunungKidul, Yogyakarta, Indonesia. Procedia Environmental Sciences, 20, 785-794. https://doi.org/10.1016/j.proenv.2014.03.095

Risko, E. F., \& Gilbert, S. J. (2016). Cognitive offloading. Trends in Cognitive Sciences, 20(9), 676-688. https://doi.org/10.1016/j.tics.2016.07.002

Rytkönen, A. (1931). Savupirttien kansaa. WSOY.

Schelling, T. C. (2006). Micromotives and Macrobehavior. WW Norton \& Company.

Scott, J. C. (1998). Seeing Like a State: How Certain Schemes to Improve the Human Condition Have Failed. Yale University Press.

Simon, H. A. (1956). Rational choice and the structure of the environment. Psychological Review, 63(2), 129-138. https://doi.org/10.1037/h0042769

Simon, H. A. (1972). Theories of bounded rationality. In C. B. McGuire \& R. Radner (Eds.), Decision and Organization (pp. 161-176). Elsevier.

Simon, H. A. (1990). Invariants of human behavior. Annual Review of Psychology, 41(1), 1-20. https://doi.org/10.1146/annurev.ps.41.020190.000245

Simon, H. A. (2000). Bounded rationality in social science: Today and tomorrow. Mind \& Society, 1, 2539.

Slanski, K. E. (2012). The Law of Hammurabi and its audience. Yale JL \& Human., 24, 97.

Smyth, D., \& Isherwood, M. (2016). Protecting sea country: Indigenous people and marine protected areas in Australia. In G. Wescott \& J. Fitzsimons (Eds.), Big, Bold and Blue: Lessons from Australia's marine protected areas (pp. 307-325). CSIRO Publishing.

Steffen, W., Broadgate, W., Deutsch, L., Gaffney, O., \& Ludwig, C. (2015). The trajectory of the Anthropocene: The Great Acceleration. The Anthropocene Review, 2(1), 81-98. https://doi.org/10.1177/2053019614564785

Stone, M. H. (2014). The cubit: A history and measurement commentary. Journal of Anthropology, 2014.

Sull, D. N., \& Eisenhardt, K. M. (2015). Simple Rules: How to Thrive in a Complex World. Houghton Mifflin Harcourt.

Sunstein, C. R. (2005). Moral heuristics. Behavioral and Brain Sciences, 28(4), 531-541.

Taylor, F. W. (1919). The principles of scientific management. Harper \& brothers.

Tennie, C., Call, J., \& Tomasello, M. (2009). Ratcheting up the ratchet: On the evolution of cumulative culture. Philosophical Transactions of the Royal Society of London. Series B, Biological Sciences, 364(1528), 2405-2415. https://doi.org/10.1098/rstb.2009.0052 
Thaler, R. H., \& Sunstein, C. R. (2008). Nudge: Improving Decisions about Health, Wealth, and Happiness. Yale University Press.

Todd, P. M., \& Gigerenzer, G. (2012). Ecological Rationality: Intelligence in the World. OUP USA.

Turnbull, D. (1993). The ad hoc collective work of building Gothic cathedrals with templates, string, and geometry. Science, Technology, \& Human Values, 18(3), 315-340. https://doi.org/10.1177/016224399301800304

Tversky, A., \& Kahneman, D. (1974). Judgment under uncertainty: Heuristics and biases. Science, 185(4157), 1124-1131. https://doi.org/10.1126/science.185.4157.1124

Van Der Stuyf, R. R. (2002). Scaffolding as a teaching strategy. Adolescent Learning and Development, 52(3), 5-18.

Viscusi, W. K. (1999). Corporate risk analysis: A reckless act. Stanford Law Review, 52(3), 547-598.

Waldman, K. B., Todd, P. M., Omar, S., Blekking, J. P., Giroux, S. A., Attari, S. Z., Baylis, K., \& Evans, T. P. (2020). Agricultural decision making and climate uncertainty in developing countries. Environmental Research Letters, 15(11), 113004. https://doi.org/10.1088/1748-9326/abb909

Wattles, J. (1996). The Golden Rule. Oxford University Press.

West, G. B. (2017). Scale: The Universal Laws of Growth, Innovation, Sustainability, and the Pace of Life in Organisms, Cities, Economies, and Companies. Penguin.

Wilensky, U. (1998). NetLogo Life model. Center for Connected Learning and Computer-Based Modeling, Northwestern University, Evanston, IL. http://ccl.northwestern.edu/netlogo/models/Life

Wilensky, U. (1999). NetLogo. https://ccl.northwestern.edu/netlogo/

Wilensky, U., \& Rand, W. (2015). An Introduction to Agent-Based Modeling: Modeling Natural, Social, and Engineered Complex Systems with NetLogo. MIT Press.

Wilke, A., \& Todd, P. M. (2010). Past and present environments: The evolution of decision making. Psicothema, 22(1), 4-8.

Wilson, R. A., \& Foglia, L. (2011). Embodied cognition. Stanford Encyclopedia of Philosophy. https://plato.stanford.edu/entries/embodied-cognition/

Xu, C., Kohler, T. A., Lenton, T. M., Svenning, J.-C., \& Scheffer, M. (2020). Future of the human climate niche. Proceedings of the National Academy of Sciences, 117(21), 11350-11355. https://doi.org/10.1073/pnas.1910114117 